\title{
Off-Body Boundary-Layer Measurement Techniques Development for Supersonic Low-Disturbance Flows
}

\author{
Lewis R. Owens", Michael A. Kegerise ${ }^{\dagger}$ and Stephen P. Wilkinson ${ }^{*}$ \\ Flow Physics and Control Branch NASA Langley Research Center, Hampton, VA 23681
}

\begin{abstract}
Investigations were performed to develop accurate boundary-layer measurement techniques in a Mach 3.5 laminar boundary layer on a $7^{\circ}$ half-angle cone at $0^{\circ}$ angle of attack. A discussion of the measurement challenges is presented as well as how each was addressed. A computational study was performed to minimize the probe aerodynamic interference effects resulting in improved pitot and hot-wire probe designs. Probe calibration and positioning processes were also developed with the goal of reducing the measurement uncertainties from $10 \%$ levels to less than $5 \%$ levels. Efforts were made to define the experimental boundary conditions for the cone flow so comparisons could be made with a set of companion computational simulations. The development status of the mean and dynamic boundary-layer flow measurements for a nominally sharp cone in a lowdisturbance supersonic flow is presented.
\end{abstract}

\section{Nomenclature}

$\mathrm{L}_{\mathrm{B}} \quad=$ length of jeweler's broach support prongs ahead of the wedge body tip (mm)

$\mathrm{L}_{\mathrm{P}} \quad=$ length of needle support prongs ahead of the wedge body tip $(\mathrm{mm})$

$\mathrm{L}_{\mathrm{T}} \quad=$ length of pitot pressure tube ahead of the wedge body tip (mm)

$\mathrm{M}_{\infty} \quad=$ free stream Mach number

$\mathrm{M}=$ boundary-layer Mach number

$\mathrm{M}_{\mathrm{e}} \quad=$ boundary-layer edge Mach number

$\mathrm{P} \quad=$ cone surface static pressure $(\mathrm{kPa})$

$\mathrm{P}_{\mathrm{o}} \quad=$ total pressure $(\mathrm{kPa})$

$\rho \mathrm{U}=$ mass flux $\left(\mathrm{kg} / \mathrm{m}^{2} \mathrm{~s}\right)$

$(\rho \mathrm{U})^{\prime} \quad=$ fluctuating mass flux $\left(\mathrm{kg} / \mathrm{m}^{2} \mathrm{~s}\right)$

$(\rho \mathrm{U})_{\mathrm{e}} \quad=$ mass flux at the boundary-layer edge $\left(\mathrm{kg} / \mathrm{m}^{2} \mathrm{~s}\right)$

$\mathrm{Re} / \mathrm{m}=$ unit Reynolds number per meter

$\mathrm{S}=$ cone surface length along a ray referenced to the apex (mm)

$\mathrm{T}_{\mathrm{O}} \quad=$ total temperature $(\mathrm{K})$

$\mathrm{T}_{\mathrm{w}} \quad=$ hot-wire temperature $(\mathrm{K})$

$\mathrm{t}_{\mathrm{rad}} \quad=$ radius of wedge probe body tip $(\mathrm{mm})$

$\mathrm{w}=$ width of wedge probe body tip $(\mathrm{mm})$

$x=$ axial distance referenced to the cone apex $(\mathrm{mm})$

$\Delta x=$ length of quiet test core $(\mathrm{cm})$

$\mathrm{y} \quad=$ wall-normal distance $(\mathrm{mm})$

$\mathrm{z}=$ wall normal distance as defined for the probe redesign CFD only $(\mathrm{mm})$

$\delta=$ boundary-layer thickness $(\mathrm{mm})$

$\theta \quad=$ cone azimuthal angle $(\mathrm{deg})$

$\tau \quad=$ hot-wire overheat ratio

$\eta \quad=$ hot-wire recovery factor

over bar $=$ mean value of the quantity

\footnotetext{
${ }^{*}$ Research Scientist, M.S. 170. Senior Member AIAA.

${ }^{\dagger}$ Research Scientist, M.S. 170. Senior Member AIAA.

${ }^{*}$ Research Scientist, M.S. 170. Senior Member AIAA.
}

1 of 22

American Institute of Aeronautics and Astronautics 


\section{Introduction}

$\mathrm{W}$ HILE it is generally agreed that high-speed boundary-layer transition research is a vital need of the aeronautics community, there is probably less agreement on the precise goals of such research. The issue seems to depend on whether one's perspective is that of long-term fundamental research or the development of project related engineering tools. In the fundamental approach, the goals are generally the prediction and/or control of transition onset using physics-based modeling within a classical hypothesis-testing framework. From an applied engineering perspective, generally associated with actual flight hardware, the goals are often shorter term and seek to control transition or reduce uncertainty in onset location to an acceptable, case-dependent level using available means including theory, simulations, ground and flight testing, and tend to rely on empirical data correlations ${ }^{1}$ or the semi-empirical n-factor method. ${ }^{2}$

The need for approximate or empirical engineering methods clearly stems from the formidable analytical and experimental problems on the scientific front. These problems arise mainly from the poorly understood nature of relevant environmental disturbances in flight and the process by which such disturbances are internalized in the boundary layer (receptivity), amplify and breakdown. This includes such factors as: surface roughness, free stream disturbances (sound, vorticity and entropy fluctuations), effects of atmospheric aerosols and particulates, electrical phenomena (e.g., static discharges) and structural vibrations. ${ }^{3}$ At least part of this lack of understanding arises from well known diagnostic limitations on the kinds of experimental data that can be accurately measured in flight, wind tunnels, and ballistic ranges.

In order to advance the physics-based modeling approach and bridge the gap between current analysis capabilities and the engineering needs of vehicle designers, including effective transition control methodologies, NASA formed a multi-faceted high-speed transition program under the Fundamental Aeronautics Program (FAP) within the Supersonics Project (Supersonic Cruise Efficiency-Airframe, SCE-A) and the Hypersonics Project (Aerodynamics, Aerothermodynamics and Plasmadynamics, AAP). Additional related transition work outside of NASA is funded through various NASA Research Announcements (NRA's) and the National Hypersonics Center for Transition-to-Turbulence at Texas A\&M University (funded jointly with the AFOSR). The goal of these efforts is to develop and employ state-of-the-art experimental and computational tools with a fresh look at high-speed boundary-layer transition. The program exists outside of any vehicle development endeavor and seeks to advance analysis and control capabilities related to important high-speed boundary-layer transition issues.

The basic approach of the various teams is to analyze fundamental unit problems associated with high-speed boundary-layer transition on simple conical, planar, wedge, and biconvex geometries using closely coordinated experimental and computational tools. The rationale behind this approach is that without a clear understanding of fundamental processes and mechanisms, including the ability to simulate and control such effects, additional model complexity offers no added value and, in fact, such complexity may inhibit overall scientific progress. Direct Numerical Simulations (DNS) of several of these unit problems can be found in previous computational investigations. ${ }^{4-7}$ The work reported in this paper is funded under the Langley Supersonics Project and introduces planned studies on a slender $7^{\circ}$ half-angle cone subjected to variations in angle of incidence, nose bluntness, surface roughness (discrete and distributed), acoustic free stream disturbances, and dynamically-actuated surface inputs. Specifically, this paper discusses development of the hardware, and the techniques and analysis required for pitot and hot-wire off-body flow diagnostics. Mean and dynamic boundary-layer measurements for a smooth, sharp tip $7^{\circ}$ half-angle cone at $0^{\circ}$ angle of attack in the quiet flow of the Supersonic Low Disturbance Tunnel (SLDT) are presented. In addition, the computational effort to design a boundary-layer probe body with minimal flow interference is briefly presented.

\section{Experimental Apparatus and Method}

\section{A. Facility}

The experiments were conducted in the Supersonic Low Disturbance Tunnel (SLDT) at the NASA Langley Research Center. This "quiet" wind tunnel facility produces a Mach 3.5 free stream with RMS static pressure fluctuations that are less than $0.1 \%$ of the mean static pressure. Since boundary-layer transition is particularly sensitive to the disturbance environment, testing in a low-noise facility, such as the SLDT, is necessary to simulate transition in the low disturbance environment encountered during high-altitude flight. Details on the facility operation and performance characteristics are provided in Refs. 8-11, so here we only provide a brief overview of the facility similar to the one presented in Kegerise, Owens, and King. ${ }^{12}$ Tests are performed in this tunnel with either a 2-D nozzle or an axisymmetric nozzle. For the cone research described in this paper, the axisymmetric nozzle ${ }^{11}$ was used.

2 of 22

American Institute of Aeronautics and Astronautics 
Figure 1a shows an isometric cutaway view that illustrates the boundary-layer suction slot and the electroformed contour of the Mach 3.5 axisymmetric nozzle. A schematic of the quiet test core with the bleed valve open is shown in Fig. 1b. The bleed slot, shown upstream of the nozzle throat, removes the boundary layer on the nozzle walls from the subsonic approach. Then, the laminar boundary layers evolving on the highly polished nozzle walls eventually transition, and at that point, noise is radiated from the supersonic transitional and turbulent boundary layer eddies. These acoustic disturbances are propagated nearly parallel to Mach lines originating from the convecting disturbances in the nozzle boundary layer (i.e., transition onset) to form the downstream boundary of the quiet test core. Mach lines originating at the upstream edge of the uniform Mach 3.5 flow define the upstream boundaries of the quiet test core. Since transition on the nozzle walls moves upstream with increasing unit Reynolds number, the physical length of the quiet test core is a decreasing function of unit Reynolds number. The Reynolds number based on the quiet test core length increases with unit Reynolds number until laminar flow in the nozzle is lost. The quiet test core, as defined here, provides a flow region where wind-tunnel models can be tested in a lownoise environment (measured $\tilde{p}_{\infty} / \bar{p}_{\infty}$ is less than $0.1 \%$ ).

Prior to the cone model installation in the SLDT, an experiment was performed to characterize the disturbance environment of the Mach 3.5 axisymmetric quiet nozzle. The free stream disturbances were measured along the nozzle centerline with a hot-wire anemometer. The hot wire was operated in the constant-temperature mode at a high overheat ratio $\left(\tau \approx 0.9\right.$ where $\left.\tau=\left(T_{w}-\eta \cdot T_{o}\right) / T_{o}\right)$ to measure mass-flux fluctuations. The measurements were started $45 \mathrm{~cm}$ downstream from the nozzle throat, which is the upstream boundary of the Mach 3.5 quiet core, and ended $90 \mathrm{~cm}$ downstream from the throat. The normalized RMS mass-flux fluctuations, $\overline{(\rho U)^{\prime}} / \overline{(\rho U)}$, as a function of distance from the nozzle throat, $x$, are presented in Fig. 1c. Mass-flux power spectral densities (PSD) for selected $x$-locations are shown in Fig. 1d. All data were acquired at a free stream unit Reynolds number of $R e / m=9.81 \times 10^{6}$.

For most of the centerline survey region, the RMS mass-flux is $\sim 0.07 \%$, which corresponds to the anemometer noise floor. By $80.5 \mathrm{~cm}$ from the throat, the RMS mass-flux reaches the $0.1 \%$ threshold that is commonly used to demarcate the end of the quiet-flow region. ${ }^{8}$ With that definition, the quiet test core length for the present flow conditions is $\Delta x=35.5 \mathrm{~cm}$ and the Reynolds number based on that length is $R e_{\Delta x}=3.48 \times 10^{6}$. Beyond $80.5 \mathrm{~cm}$, the RMS mass-flux increases rapidly due to radiated noise from the transitional nozzle wall boundary layer.

At $x$-locations within the quiet test core $(x<80.5 \mathrm{~cm})$, the mass-flux PSD are dominated by energy that increases with the frequency squared. That $f^{2}$-noise is associated with electronic noise inherent to the constant-temperature anemometer ${ }^{13}$ and accounts for most of the energy in the RMS values presented in Fig 1c. There is, however, lowfrequency energy, in the $100 \mathrm{~Hz}$ to several kilohertz range, that lies above the anemometer noise floor and grows in the downstream direction. The exact source of that energy is unknown at this time and requires further investigation. Nevertheless, the energy contained in that frequency band is so small that it accounts for very little of the total signal energy observed in the quiet test core and furthermore, the low frequencies should not be dynamically relevant to the transition phenomena we are currently investigating. Outside the quiet test core $(x \geq 80.5 \mathrm{~cm})$, the mass-flux PSD display a significant increase in energy across a broad frequency range - an increase that is due to radiated noise from the transitional nozzle wall boundary layer.

\section{B. Cone Model}

The cone model is $381 \mathrm{~mm}$ in length with a $7^{\circ}$ half angle. The model was designed to have a large replaceable nose tip and a common aft frustum with the part line located at $x=190.5 \mathrm{~mm}$. This design places any nose tip joint surface step downstream of the nose tip region to make the step smaller relative to the boundary-layer thickness. Dividing the cone in this manner also allowed for the design of various cone tips to enable parametric variations in nose tip bluntness as well as integration of dynamic surface control input devices in later phases of the research program. At this point in the investigation, several cone tips of different nose bluntness have been built. The cone model was designed to avoid thin-walled construction techniques because of previous fabrication experiences where the nose geometry requirements were not met. The thick-walled approach improved the fidelity of the cone model geometry, but posed challenges in terms of installing instrumentation and thermal conditioning of the model during testing. The model has a highly polished surface with roughness levels of about $0.1 \mu \mathrm{m}$ RMS.

The model has ten surface static pressure orifices $(0.508 \mathrm{~mm}$ dia.) located along one cone frustum ray $(228.6 \mathrm{~mm}$ $\leq x \leq 342.9 \mathrm{~mm}$ spaced every $12.7 \mathrm{~mm}$ ) as shown in Fig. 2a. Model temperatures were monitored using six type-K thermocouples, three located in the cone tip part at $x=76.2,101.6$, and $127 \mathrm{~mm}$ and three located in the cone frustum part at $x=254,292.1$, and $330.2 \mathrm{~mm}$. Details on the specific thermocouple locations are shown in Fig. $2 \mathrm{~b}$. The cone model configuration tested had the sharpest tip achievable through current sharpening techniques using electrical discharge machining (EDM), estimated to be $\sim 0.05 \mathrm{~mm}$ tip radius. A close-up picture of the actual tip

$\underline{3 \text { of } 22}$

American Institute of Aeronautics and Astronautics 
geometry is shown in Fig. 3 in comparison to an ideal straight, sharp tip. The deviation between the ideal and actual tip geometry is due to slight elastic bending of the tip during machining processes.

A 3-axis traverse was designed to provide probe motion in the wall-normal, axial, and azimuthal directions. Pictures of the cone model and the off-body traverse system are shown in Fig. 4. The starting point for the model traverse and probe tip designs was based on previous research in this area. ${ }^{14,15}$ For this phase of the sharp-tip cone investigation, the wall-normal and the axial probe motions are currently remotely controlled. The azimuthal position was varied manually but will be automated for future tunnel entries.

\section{Boundary-Layer Probes}

The starting point for the probe-tip design came from the work of Cavalieri ${ }^{14}$ and Matlis. ${ }^{15}$ The probes used by Matlis were of particular interest because of his recent testing experience (2003) on a similar cone model in the SLDT where he collected both pitot and hot-wire boundary-layer probe data. The probes used in the Matlis study were of such length that we had concerns about potential prong vibrations affecting the hot wire dynamic data. Matlis based his probe design on the wedge tip developed in the Cavalieri study. Using this wedge design as the basis, Matlis performed a probe length experimental study to determine what length was needed to minimize the probe interference effects in the lower part of the boundary layer. This length study tended to agree with the upstream influence distance criteria of ten times the boundary-layer height as reported in the mid-1950's study by Morkovin and Bradfield. ${ }^{16}$ Matlis chose a nominal boundary-layer height of $1.27 \mathrm{~mm}$ as a reference so that his probe extended $12.7 \mathrm{~mm}$ upstream of the probe wedge to minimize its influence.

Matlis also performed a probe height study to determine how large the pitot tube height could be before it causes an overshoot in the Mach number at the outer edge of the boundary layer, which is one characteristic of probe interference. If the probe height exceeds a certain fraction of the boundary layer thickness, then a strong shock/boundary-layer interaction can cause a flow separation ahead of the probe location to produce accelerated flow toward the outer edge of the boundary layer. In the late 1950 's, Kendall ${ }^{17}$ performed a pitot probe diameter study of this overshoot for a Mach 5.8 flow over a flat plate and he found that this overshoot was avoided if the pitot tube height was no more than about 12.5 percent of the boundary-layer thickness. However, it was not clear if this was the upper tube height limit because the next size up in the study was 25 percent of the boundary-layer thickness. Matlis demonstrated boundary-layer profile measurements with no overshoot for a pitot probe height of $0.1 \mathrm{~mm}$ in a $0.5 \mathrm{~mm}$ boundary layer on a cone in a Mach 3.5 cone flow. This corresponds to a probe height that is 20 percent of the boundary-layer height for a Mach 3.5 axisymmetric cone flow. We decided to use an upper limit probe height guideline of 20 percent for the pitot probe design.

For the present study, we wanted to design a complimentary set of probes to provide both pitot pressure and hotwire measurements with minimal probe body aerodynamic interference in a supersonic laminar boundary layer. These new probe designs require the use of shorter and stiffer hot-wire support prongs to minimize prong vibration that could potentially distort the dynamic profile measurements. The previous probe designs required some modifications to accomplish this goal. Therefore, we decided to conduct a CFD study to guide this probe design effort.

The mean-flow computations were performed using NASA's TetrUSS. ${ }^{18,19}$ We decided to model a probe at a specific height in the boundary layer above a sharp leading-edge flat plate where the local Mach number was 1.2. This Mach number was chosen because it corresponds to the lowest measurable point in a supersonic boundary layer where valid hot-wire measurements are possible. The most severe conditions were chosen for these CFD cases so the insights gained could be applied towards a boundary-layer probe design with minimal flow interference effects. These stringent conditions included positioning the probe $50.8 \mathrm{~mm}$ downstream of the flat plate leading edge to probe the thinnest boundary layer we expected to encounter in the research as well as selecting the highest planned unit Reynolds number test condition; $\mathrm{Re} / \mathrm{m} \sim 2 \times 10^{7}$ at $\mathrm{P}_{\mathrm{o}}=344.7 \mathrm{kPa}$ and $\mathrm{M}_{\infty}=3.5$.

The computational surface grids and some of the results found in the probe study are shown in Fig. 5. Geometries for six out of the ten study cases are shown in Fig. 5a to represent the three primary aspects of the probe redesign effort. Cases 3 and 5 represent the redesign of the wedge probe tip to minimize the upstream influence through the subsonic portion of the boundary layer. In this part of the study, we found that minimizing both the wedge tip width and radius were necessary to decrease the upstream pressure interference. The wedge width was decreased to the minimum allowable for an effective hot-wire prong separation distance and the tip radius down to the practical fabrication limit of $0.0635 \mathrm{~mm}$.

Cases 2 and 10 represent the probe type comparison aspect of the computational study, which assessed the potential differences in probe body interference effects for hot-wire and pitot pressure probes. From this part of the study, we learned that both hot-wire and pitot pressure probes could have the same length upstream of the wedge tip

$\underline{4 \text { of } 22}$

American Institute of Aeronautics and Astronautics 
to provide a complimentary set of boundary-layer measurements with the same minimal probe body interference effects.

The last two cases shown, 6 and 7, in Fig. 5a represent a prong length study for the redesigned hot-wire probes. The long hot-wire probe shown in case 6 is for an upstream influence extent of about ten times the boundary-layer height, which is shown in the mass-flux profile plot in Fig. 5b. The short hot-wire probe shown in case 7 of Fig. 5a is half the length of the long probe to determine if designing for an upstream influence of only five times the boundary-layer height is possible. The short probe length was the chosen minimum because the computational results showed that the wedge tip caused significant flow distortion effects for shorter probe lengths.

The final results of the computational hot-wire probe redesign are presented in Fig. 5b. The three cases examined here included: (case 2) the original hot-wire probe design using the jeweler's broach from the Matlis study, ${ }^{15}$ (case 6) the redesigned long hot-wire probe, and (case 7) the redesigned short hot-wire probe. The computed mass-flux profiles show that both of the redesigned hot-wire probes agree more closely (worst case probe interference uncertainty of $2 \%$ ) with the expected similarity profile than does the original hot-wire probe design. The difference for the original design arises from the large flat beveled faces of the prongs producing more local interference independent of the probe body proximity to the prong tip. The redesigned hot-wire probes used needle prongs (modeled as a cone/cylinder geometry) to produce much less local flow distortion. The computed total temperature profiles are shown in the lower left portion of Fig. 5b. Of the three hot-wire probe cases studied, the short prong probe design was closest to the similarity result. The Mach contours on the centerline plane between the hot-wire support prongs are presented on the right side of Fig $5 \mathrm{~b}$ for each of the three cases. These contour plots show the probe body wedge tip upstream influence depending on its proximity to the flat plate surface below. More details about the resulting NASA probe designs are shown briefly in the photos presented in Fig. 6. More extensive details on the redesign and validation of the new boundary-layer probes may be found in Owens and Kegerise. ${ }^{20}$

\section{Boundary-Layer Measurements}

As discussed in Kegerise, Owens, and King, ${ }^{12}$ obtaining mean and fluctuating measurements inside thin boundary layers $(\delta \sim 1 \mathrm{~mm})$ on small-scale models is quite challenging. Accurate measurements require a high spatial resolution in the wall-normal direction and a frequency response in excess of $100 \mathrm{kHz}$; therefore hot-wire anemometry was chosen as the primary instrument. However, when performing quantitative hot-wire measurements in a thin supersonic boundary layer, several key issues must be addressed. These measurement issues include minimizing the mean-flow distortion by the probe (as discussed in detail in the previous section), accurate wallnormal positioning, and accounting for the sensitivity of the hot-wire calibration to multiple flow variables. Using procedures discussed in detail within Ref. 12, we were able to set the wall-normal (y-axis) probe positions during a boundary-layer survey to within $\pm 6.5 \mu \mathrm{m}$. The positioning along the cone surface is not as critical as the wall-normal positioning. However, it is still important to know this position with a reasonable degree of accuracy to avoid what appear to be shifts in the virtual origin of the boundary layer. The streamwise (x-axis) probe travel along the cone surface ranges from $56 \mathrm{~mm}$ to $298 \mathrm{~mm}$ downstream of the cone apex with an $\mathrm{x}$-axis resolution, as measured by a laser tracker, of $0.081 \mathrm{~mm}$. The azimuthal angle was set using a torpedo level on a side surface of the traverse block.

\section{E. Matching Boundary Conditions}

All relevant boundary conditions need to be considered when making comparisons between CFD and experiments. In the cone test, we systematically went through the boundary conditions and compared the boundarylayer measurements to the computational results at every step. When there was a significant difference between the experimental measurements and the computed mean flow results, we searched to discover what measurement error was being made or what boundary condition was not properly represented until the cause for the difference was determined. This extensive effort to match the mean flow data between the experiment and computations was required in order to meet the goal of identification and control of flow instability mechanisms inside laminar supersonic boundary layers. For this type of flow stability analysis, it is important to match the basic mean flows to establish confidence in the results. If the mean flows for the computations and experiment do not match, then the origins of these stability differences is unclear and confidence is lost.

At the beginning of the experiment, the first challenge faced was to acquire repeatable sets of boundary layer measurements with the pitot pressure probe. Because the thick-wall construction presented some thermal conditioning issues, we took a series of boundary-layer surveys at a given location (toward the rear of the cone) to determine how much model conditioning was necessary before a consistent set of boundary-layer measurements could be made. The SLDT is a blow-down facility, but is capable of running up to $\sim 2$ hours at these test conditions depending on the model blockage. Each pitot pressure probe boundary-layer survey acquired took $\sim 8-10$ minutes to

$\underline{5 \text { of } 22}$

American Institute of Aeronautics and Astronautics 
complete. We observed that after 20 minutes (about two surveys) the cone model reached sufficient thermal equilibrium to produce a repeatable series of boundary-layer profiles.

A set of thermocouple criteria for this model was determined so that repeatable pitot pressure profile measurements were consistently obtained if these criteria were met. An example of the model temperatures resulting from the thermal conditioning process is shown in Fig. 7 for three boundary-layer surveys representing an earlier unconditioned state, a conditioned state after just reaching the acceptable profile repeatability criteria, and a final state toward the end of a maximum run time period when the model has achieved thermal equilibrium. For the unconditioned state, the temperatures at the six model locations vary significantly throughout the boundary-layer survey. The other two conditioned thermal states show much less cone temperature variation at a given cone station during a boundary-layer survey and appear to be approaching a linear temperature distribution. The dashed line was designated as the thermal wall boundary condition for the CFD results finally used for comparison with the experimental measurements as opposed to the adiabatic wall condition assumed in the initial computations. Only the tip region of the cone reaches an adiabatic wall condition and the remainder of the cone length has an upward trend in temperature levels the closer the location is to the model support sting.

After establishing a consistent method to control the model thermal boundary condition, we focused next on determining the cone model alignment with the nozzle flow. In the fabrication of the model and its support system, tight tolerances were maintained to keep the model aligned with the tunnel test section. However, the axisymmetric nozzle is cantilevered from an upstream bulkhead and is not necessarily in exact alignment with the test section due to its size, weight, and potential installation differences. Therefore it was necessary to determine how closely the model and the nozzle flow were aligned. We checked this alignment using both the cone surface static pressures and the boundary-layer profile data. Both types of data were used to check the consistency of the alignment analysis.

Cone alignment results from the analysis of the static pressure measurements are shown in Fig. 8. Figure 8a gives the cone surface pressure ratios on the back half of the cone. Each experimental (EXP) curve represents a single tunnel run with the single cone model pressure ray rotated to one of four selected azimuthal angles $\left(0^{\circ}, \pm 90^{\circ}\right.$ and $180^{\circ}$ ). Fig. $8 \mathrm{~b}$ presents a schematic of the different azimuthal locations for each cone ray while looking upstream. This sketch gives a frame of reference for understanding the cone model misalignment with the nozzle flow. In Fig. 8a, the experimental and computational pressure ratios for various cone axial stations are presented and the relative location of the nozzle exit is indicated by the vertical solid black line at $\mathrm{S}=265 \mathrm{~mm}$. The computational (CFD) mean pressure ratio level shown as the solid red line in the plot was adjusted to $\mathrm{M}_{\infty}=3.48$ from the computed 3.5 free stream condition. This adjustment was made to correspond to the actual nozzle free stream Mach level observed in empty nozzle centerline pitot probe surveys acquired in the previous axisymmetric nozzle flow characterization experiments. The CFD result represents the cone mean pressure ratio level for a model exactly aligned with the nozzle flow. A $\pm 1 \%$ variation from the CFD result is shown for reference for pressure level difference comparisons.

The first four experimental curves are presented in two groups represented by either a circle or a square symbol. Each symbol is associated with a cone surface ray pair separated by $180^{\circ}$ (diametrically opposed). The two open symbol EXP curves, $0^{\circ}$ and $-90^{\circ}$, generally show a higher compression level relative to the mean CFD level. The two filled symbol EXP curves show a lower compression level. Using the average pressures for the first five stations, differences across the vertical and horizontal diameters were calculated to provide angle offsets. These pressure differences were converted to angle offsets by computing what surface pressure change would occur with a small perturbation of the cone half angle. These perturbation angles, $\sim 0.04^{\circ}$ nose down and $\sim 0.08^{\circ}$ nose left, are indicated in Fig. 8b. After estimating the misalignment, we adjusted the pitch using a shim under the front of the model support strut and again measured the pressures along the $0^{\circ}$ ray (see the black-filled circle curve in Fig. 8a). The pitch adjustment removed most of the extra compression relative to the CFD level. There was no adjustment capability in the yaw plane to remove the nose left misalignment for this tunnel test. Finally, the last 5 pressure stations consistently show pressure peaks for each ray location measured. The axisymmetric nozzle has a filled groove resulting from a machining error located inside the nozzle $\sim 160 \mathrm{~mm}$ upstream of the exit. Although attempts were made to fill this groove smoothly, recent empty nozzle free stream surveys along the centerline show signs of the disturbance generated by this filled groove. The cone pressure measurements also show this disturbance.

Cone alignment was also assessed using the off-body boundary-layer survey measurements and the results of this analysis are shown in Fig. 9. The most rearward axial station was the most sensitive to flow misalignments and these profiles were used to check the consistency of the static pressure misalignment analysis. The azimuthal angles chosen for the boundary-layer profiles were $\pm 45^{\circ}$ and $\pm 135^{\circ}$ because these angles are spread uniformly between the static pressure ray measurement stations and do not cause the probe arm to interfere with the model support strut. Fig. 9a shows the boundary-layer profiles at the four selected azimuthal stations before any model angle adjustment was made. The chosen data symbols grouped the two azimuthal stations on each of the two primary diameters

$\underline{6 \text { of } 22}$

American Institute of Aeronautics and Astronautics 
(similar to the grouping used in the static pressure analysis except for the $45^{\circ}$ clocking). The largest spread in the boundary-layer profile data is seen for the $-45^{\circ}$ and $+135^{\circ}$ azimuthal stations, which is the diameter most aligned with the combined misalignment vector estimated from the static pressure analysis. After the pitch misalignment was adjusted, another set of boundary-layer profiles was taken to determine if the adjustment reduced the difference between the $-45^{\circ}$ and $+135^{\circ}$ azimuthal stations. Figure $9 \mathrm{~b}$ shows that the adjustment reduced the difference between these two profile stations and this difference looked similar to that observed for the $+45^{\circ}$ and $-135^{\circ}$ stations in Fig. 9 a. This would be expected if only a yaw misalignment remains. These findings suggest that the rearward boundarylayer profiles are a useful method for getting good flow alignment of the cone model with the nozzle flow for $0^{\circ}$ angle of attack tests, thereby eliminating the need to rotate the cone model itself in order to acquire the static pressure ray data for alignment assessments.

\section{F. Boundary-Layer Probe Length Study Check}

After establishing the methods necessary to obtain consistent sets of boundary-layer profile data, the next step was to decide what length probes were appropriate for acquiring the final set of off-body measurements for the sharp-tip cone at $0^{\circ}$ angle of attack. We selected the $+135^{\circ}$ cone ray to perform boundary-layer surveys with the short pitot probe for comparison at the same six axial stations where long pitot probe surveys were made. This comparison is shown in Fig. 10. The computational results are also included for reference. Both probe data sets appear to give similar boundary-layer profiles, which are a slightly thicker than the computed profiles. This slight thickness bias is expected due to the remaining model yaw misalignment that was discussed in the previous section. Given the similar profile measurements, we decided to proceed through the rest of the testing using the short length probes. It is important to note that the driver for this decision was the hot wire, where the expectation was that the shorter-prong probe would be less susceptible to prong vibration. All the remaining boundary-layer profile data presented in this report was obtained with the short probes.

\section{Discussion of Results}

\section{A. General Cone Flow Field}

Before discussing the final off-body boundary-layer surveys for this test, it is useful to look at the overall flow field in which these measurements were made. In Fig. 11, a schlieren image of the flow around the cone is shown for $\mathrm{M}_{\infty}=3.5, \mathrm{P}_{\mathrm{o}}=172.4 \mathrm{kPa}, \mathrm{T}_{\mathrm{o}}=311 \mathrm{~K}$, and $R e / m \sim 10^{7}$. Note only about $116 \mathrm{~mm}$ of the cone model surface length is visible beyond the nozzle exit in this image. That is because the tip of the cone is positioned inside the nozzle 25.4 $\mathrm{mm}$ downstream from the start of the uniform Mach flow region. The probe traverse is shown at a position on the top of the cone $\left(\theta=0^{\circ}\right)$ where the pitot tube tip is near the axisymmetric nozzle exit plane. At these test conditions, in quiet flow, a laminar boundary layer is established along the entire length of the cone as indicated by the smoothedged, narrow, bright light band on the bottom of the cone model in this image. Also note the absence of any shock reflections off the nozzle walls causing interference with the cone model flow. The overall flow field appears appropriate to study the boundary layer on a cone model in a low disturbance flow.

\section{B. Mean Boundary-Layer Profile Measurements}

After completing the cone model system setup and defining the appropriate boundary conditions, the next step was to acquire a complete set of mean and dynamic boundary-layer profile measurements for a cone at $0^{\circ}$ angle of attack (noting that the cone was still yawed nose left $\sim 0.1^{\circ}$ ). We first focus our attention on the mean flow measurements. Figure 12 shows the boundary layer Mach profiles calculated from the short pitot probe measurements for six different axial stations along the cone length. For reference, the thickness of a dime is shown to give a sense of how small the boundary layers are in these measurements. Also shown for reference is the height of the pitot probe used to make these measurements.

In general, the profiles in Fig. 12 show the boundary-layer growth along the length of the cone. The experimental data symbols plotted correspond to two different cone rays separated by $180^{\circ}$. At each height, the data symbols show a Mach number spread, which generally falls to either side of the CFD profiles until reaching the lower parts of the boundary layer. These data are shown to give an idea of the remaining flow misalignment due to limitations in the adjustment capability for the current model support set up. The CFD plotted in this figure includes results for an aligned cone model (red solid line) and the two diametrically opposed cone rays (dotted and dashed lines) from computations with a $0.1^{\circ}$ yaw misalignment. These computational results provide a better estimate of how much misalignment $\left(\sim 0.1^{\circ}\right)$ remains between the nozzle flow and the cone model in the experiment. However, the level of agreement observed in these profiles is sufficient to indicate that the mean flows simulated by the experiment and

\section{7 of 22}

American Institute of Aeronautics and Astronautics 
the computations with matching boundary conditions are the same. Also, note the new probe design enabled measurements very close to the cone apex $(\mathrm{S}=69 \mathrm{~mm})$ in a very thin boundary layer $(\delta \sim 0.5 \mathrm{~mm})$ with little overshoot in the outer edge condition. As discussed previously, a large overshoot in the boundary-layer edge condition is an indication of the mean flow distortion caused by probe interference effects.

Although the mean profile measurement capability was established for the short pitot probe, we also obtained a set of calibrated mean short probe hot-wire measurements. In Fig. 13, boundary-layer profiles are shown for two cone axial stations, aft $(298 \mathrm{~mm})$ and forward $(95 \mathrm{~mm})$. On the left side of this figure the mean Mach number and mass-flux profiles are plotted with the corresponding computational results (solid lines). The experimental Mach profiles (symbols) are those calculated from the pitot probe measurements and are included for reference to show what height was reached for the lower Mach measurement limit of 1.2. The experimental mass-flux profiles (symbols) were calculated by applying a calibration to the mean hot-wire probe voltage measurements (see Kegerise, Owens, and King ${ }^{12}$ for details on the calibration process used). These mean hot-wire profiles also compare well with the flow aligned computational results. The right side plot shows the total temperature profile data obtained from cold-wire surveys with an applied recovery factor (a function of both the probe design and the wire Reynolds number), which was also obtained in the hot-wire calibration process.

\section{Dynamic Boundary-Layer Profile Measurements}

As we started assessing the dynamic measurements in the low disturbance flow environment, it became clear that we had some structural vibration issues interfering with the dynamic boundary-layer profile measurements, which had very low RMS mass-flux levels. The RMS mass flux fluctuation plot for the low disturbance test conditions is not presented because these measurements are somewhat contaminated by the probe arm system vibrations, which have significant structural resonant frequencies as seen by the peaks in the hot-wire voltage spectra shown in Fig. 14.

The voltage spectra shown in Fig. 14 are representative of the dynamic data points acquired during the low disturbance testing. Four voltage spectra are shown, three different boundary-layer heights from the cone model test and one calibration spectrum from the Probe Calibration Tunnel (see Kegerise, Owens, and King ${ }^{12}$ for more details). The spectrum for the height that corresponds to the boundary-layer edge $(\delta \sim 0.4 \mathrm{~mm})$ at this axial station shows numerous frequency peaks. Comparing this $\mathrm{y}=0.4 \mathrm{~mm}$ spectrum to the PCT spectrum, differences are seen in the energy distribution over the measured frequency range. The same hot-wire probe was used for both of these measurements and the primary difference is how the probe was mounted. For the PCT measurement, a sturdy support strut holds the probe in place for calibrations. For the cone measurements, the model traverse system holds the probe and the traverse mounts to the cone model support sting/strut system. The PCT measurement has no significant frequency peaks below $\sim 20 \mathrm{kHz}$ as compared to the cone model measurements and the cone measurements have more broadband energy filling in the $2 \mathrm{kHz}$ to $20 \mathrm{kHz}$ range. Some of these differences are associated with the additional joints and degrees-of-freedom present in the cone traverse/model support systems.

We asked a team of structural dynamics analysts to set up a laser vibrometer instrument to measure the vibrations of a set of reflective targets applied to the cone model/traverse structure in the tunnel to help us identify as many of the resonant structural frequencies as possible. From this effort, we found a model support strut joint required a significant redesign and that the model support strut thickness needed to be increased. The motor cables from the probe arm also needed to be rerouted to prevent the cable loop from extending downstream into the tunnel diffuser where unsteady flows move the cable and transmit these vibrations to the probe arm to affect the probe dynamic measurement. The modifications identified in the vibration assessment will not eliminate the resonant frequencies from the support system but will help to reduce the associated amplitudes and the impact on low disturbance dynamic boundary-layer profile measurements.

The planned model support modifications could not be made during this phase of the investigation. Model support structural vibration issues continued to affect the dynamic profile measurements in the low disturbance flow at these conditions. With the model set at $0^{\circ}$, we could not obtain high enough n-factors (Fig. 15) to cause transition to occur on the cone. Since the purpose of this study was to demonstrate the dynamic measurement capability, we switched from the low disturbance flow to the high disturbance one by closing the nozzle bleed valves. This noisier environment was sufficient to produce enough instability growth to transition the cone boundary layer. The calibrated short hot-wire probe was used to make a series of boundary-layer profile measurements along a given cone ray. The calibrated hot-wire mean mass-flux profile data for this condition are shown in Fig. 16. These mean profiles exhibit a laminar character for $\mathrm{S} \leq 171 \mathrm{~mm}$. For $\mathrm{S}>171 \mathrm{~mm}$, the profiles tend to turn significantly toward the cone surface at the lower heights in the boundary layer. This new profile character continues up to $\mathrm{S}=247 \mathrm{~mm}$. At the final axial station measured, the profile character has become totally different and the boundary layer thickness has grown so that the current probe wall-normal range set up could not capture its edge.

\section{$\underline{8 \text { of } 22}$}

American Institute of Aeronautics and Astronautics 
The dynamic boundary-layer profile measurements obtained for the high disturbance flow conditions are shown in Fig. 17. The RMS mass-flux profiles at different cone stations are plotted in Fig. 17a while the variation of the peak RMS mass-flux variation along a cone ray is plotted in Fig. 17b. In Fig. 17a, the RMS mass-flux profiles have the expected shape with the peak RMS mass-flux value occurring at $\sim 60 \%$ of the boundary-layer height at each axial station. The peak RMS mass-flux values begin to increase significantly as the boundary layer transitions as seen directly in Fig. 17b. These dynamic profile measurements are consistent with the current understanding of the expected boundary-layer transition behavior providing some level of confidence in the dynamic off-body flow measurement technique developed so far. The planned modifications to the probe traverse and the cone model systems are intended to minimize the vibration issues so that another attempt to acquire a similar set of dynamic profile measurements can be made in low disturbance conditions during the next cone test.

At the end of the test, we decided to acquire a set of surface pitot pressure measurements for the high disturbance conditions to compare directly to the off-body measurements. The pitot probe was installed on the model traverse and placed on the cone surface using the model fouling system. A pitot measurement was made at a series of axial stations along the same cone ray on which the dynamic profile measurements were obtained. These pitot measurements act as a Preston tube, which can be used to detect the surface location of the boundary-layer transition onset. The comparison of the off-body and surface transition measurement techniques are shown in Fig. 18. The offbody data in the upper plot of Fig. 18 uses a normalized version of the RMS data shown in Fig. 17b. The start of the peak RMS mass-flux trend is somewhat flat. This noise floor limit is not believed to be that of the anemometer. The distribution of energy measured in the boundary layer with the bleed valves closed is significantly higher than the anemometer noise floor. The flat level shown in Fig. 18 may be due to the free-stream noise that is internalized within the boundary layer and instability growth above this background noise level is not observed until further downstream. For $\mathrm{S}>150 \mathrm{~mm}$, this mass-flux trend begins to increase as the disturbances grow exponentially until the transition onset. The surface measurement technique in the bottom plot of Fig. 18, clearly shows the surface transition onset location occurring just ahead of the $250 \mathrm{~mm}$ cone station. The off-body measured transition onset is comparable to that of the surface measurement technique providing an increased level of confidence in the off-body dynamic measurement capability.

\section{Conclusion}

The details and status of the development of an off-body boundary-layer measurement technique for a $7^{\circ}$ halfangle cone model at $0^{\circ}$ angle of attack in a supersonic, low-disturbance flow were presented. A careful step-by-step process was used to establish a reasonable set of matching boundary conditions to help make a consistent comparison between the experimental and computational data. Through these comparisons, we demonstrated the capability to make accurate mean profile measurements in thin boundary layers $(\delta \sim 0.5 \mathrm{~mm})$ with minimal probe interference. The minimal probe interference was accomplished through a careful redesign effort to improve previous pitot and hot-wire probe designs using a computational analysis for guidance. The capability to make accurate dynamic profile measurements in the low disturbance flow environment is still being developed. Vibration issues and load limits associated with the cone model system prevented us from acquiring a useful set of dynamic boundary-layer profile data in a supersonic, low-disturbance flow. Planned modifications for the cone model system may alleviate these issues in future cone tests. However, it is important to note that the current off-body probe technique demonstrated the capability to acquire a useful set of dynamic profile data in a supersonic, highdisturbance flow environment.

\section{Acknowledgments}

This work was performed as part of the Supersonic Cruise Efficiency-Airframe (SCE-A) discipline of the Supersonics Project and the Aerodynamics, Aerothermodynamics, and Plasma Dynamics (AAP) discipline of the Hypersonics Project - both of which are under NASA's Fundamental Aeronautics Program (FAP). The Associate Principal Investigators of the respective disciplines, Linda Bangert and Deepak Bose, are thanked for their support. The authors thank the members of our high-speed research group in the Flow Physics and Control Branch for their many useful discussions throughout the test program and assistance in the development of test hardware: George Beeler, Frank Chen, Rudolph King, Ponnampalam Balakumar and Catherine McGinley. The authors thank P. Balakumar for the cone model mean-flow computations and stability analysis. Mark Cagle, Chris Laws, and Sandy Webb are to be recognized for the design of the cone model used in this study. Ralph Buehrle and Justin Templeton are to be recognized for their efforts to provide a set of structural vibration measurements to help us understand the vibration issues on the cone model system. Mark Roth, Tom Hall, and Wayne Geouge are recognized for their truly professional craftsmanship and innovative ideas related to the assembly of the hot-wire probes and pitot probes.

$\underline{9 \text { of } 22}$

American Institute of Aeronautics and Astronautics 
Finally, the authors thank our facility technicians: Hugh Pinkston, Rhonda Mills, Ricky Clark, and personnel in the air support group, especially John Warren, for providing the outstanding support necessary to keep our wind-tunnels operating.

\section{References}

${ }^{1}$ Horvath, T.J., Berry, S.A, Merski, N.R., et al., "Shuttle Damage/Repair from the Perspective of Hypersonic Boundary Layer Transition-Experimental Results," AIAA Paper 2006-2919, 2006.

${ }^{2}$ Chang, C-L, "LASTRAC.3d: Transition Prediction in 3D Boundary Layers", $34^{\text {th }}$ AIAA Fluid Dynamics Conference and Exhibit, Portland Oregon, AIAA Paper 2004-2542, June 28-July 1, 2004.

${ }^{3}$ Bushnell, D. M., "Research Status/Requirements and NASA Applications for Wall Layer Transition," in Transition, Turbulence and Combustion, Vol. 1, eds. Hussani, M.Y., Gatski, T.B. and Jackson, T.L., Kluwer Academic Publishers, ISBN 07923-3084-6, 1994, pp. 3-12.

${ }^{4}$ Balakumar, P. and King, R.A., "Receptivity and Transition of Supersonic Boundary Layers Over Swept Wings," $48^{\text {th }}$ AIAA Aerospace Sciences Meeting, January 4-7, 2010, Orlando, Florida, AIAA Paper 2010-1454, January 2010.

${ }^{5}$ Balakumar, P. and Kegerise, M.A., "Receptivity and Transition of Hypersonic Boundary Layers Over Straight and Flared Cones," $48^{\text {th }}$ AIAA Aerospace Sciences Meeting, January 4-7, 2010, Orlando, Florida, AIAA Paper 2010-1065, January 2010.

${ }^{6}$ Balakumar, P., "Stability of Supersonic Boundary Layers on a Cone at an Angle of Attack," 39 ${ }^{\text {th }}$ AIAA Fluid Dynamics Conference and Exhibit, June 22-25, 2009, San Antonio, Texas, AIAA Paper 2009-3555, June 2009.

${ }^{7}$ Balakumar, P., "Receptivity of Supersonic Boundary Layers Due To Acoustic Disturbances Over Blunt Cones," $37^{\text {th }}$ AIAA Fluid Dynamics Conference and Exhibit, June 25-28, 2007, Miami, Florida, AIAA Paper 2007-4491, June 2007.

${ }^{8}$ Beckwith, I.E., Creel, T.R., Chen, F.-J., and Kendall, J.M., "Free-Stream Noise and Transition Measurements on a Cone in a Mach 3.5 Pilot Low-Disturbance Tunnel," NASA TP 2180, September 1983.

${ }^{9}$ Chen, F.-J., "Boundary-Layer Transition Extent Measurements on a Cone and Flat Plate at Mach 3.5," AIAA Paper 930342, January 1993.

${ }^{10}$ Anders, J.B., Stainback, P.C., and Beckwith, I.E., "New New Technique for Reducing Test Section Noise in Supersonic Wind Tunnels," AIAA Journal, Vol. 18, No. 1, January 1980, pp. 5-6.

${ }^{11}$ Chen, F.-J., Malik, M.R., and Beckwith, I.E., “Advanced Mach 3.5 Axisymmetric Quiet Nozzle,” AIAA Paper 90-1592, June 1990.

${ }^{12}$ Kegerise, M.A., Owens, L.R., and King, R.A., "High-Speed Boundary-Layer Transition Induced by an Isolated Roughness Element," AIAA paper 2010-4999, June 2010.

${ }^{13}$ Freymuth, P., "Noise in Hot-Wire Anemometers," The Review of Scientific Instruments, Vol. 39, No. 4, April 1968, pp. 550-557.

${ }^{14}$ Cavalieri, D. A., On the Experimental Design for Instability Analysis on a Cone at Mach 3.5 and 6.0 using a Corona Discharge Perturbation Method, Master's Thesis, Illinois Institute of Technology, Chicago, IL, 1995.

${ }^{15}$ Matlis, E. H., Controlled Experiments on Instabilities and Transition to Turbulence on Sharp Cones at Supersonic Mach Numbers, Ph.D. thesis, Univ. of Notre Dame, Notre Dame, IN, 2003.

${ }^{16}$ Morkovin, M.V. and Bradfield, W.S., "Probe Interference in Measurements in Supersonic Laminar Boundary Layers," J. of the Aeronautical Sciences, Vol. 21, No. 11, Nov. 1954, pp. 785-787.

${ }^{17}$ Kendall, J.M., “An Experimental Investigation of Leading-Edge Shock-Wave Boundary-Layer Interaction at Mach 5.8,” J. of the Aeronautical Sciences, Vol. 24, No. 1, Jan. 1957, pp. 47-56.

${ }^{18}$ Frink, N. T.; Pirezadeh, S. Z.; Parikh, P. C.; Pandya, M. J. and Bhat, M. K., "The NASA tetrahedral unstructured software system (TetrUSS)," The Aeronautical Journal of the Royal Aeronautical Society, October 2000, pp. 491-499.

${ }^{19}$ Frink, N. T., "Assessment of an Unstructured-Grid Method for Predicting 3-D Turbulent Viscous Flows," AIAA Paper 96-0292, January 1996.

${ }^{20}$ Owens, L.R. and Kegerise, M.A., "Computational and Experimental Investigation of Probe Interaction with a Flat-Plate Supersonic Laminar Boundary-Layer Flow,” NASA TP in preparation.

10 of 22

American Institute of Aeronautics and Astronautics 


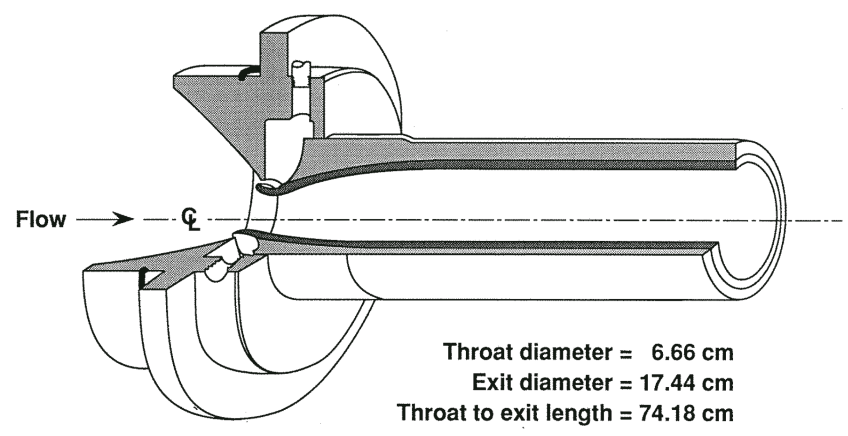

(a) Isometric cutaway view showing boundary layer suction slot and electroformed contour of the Mach 3.5 axisymmetric quiet nozzle.

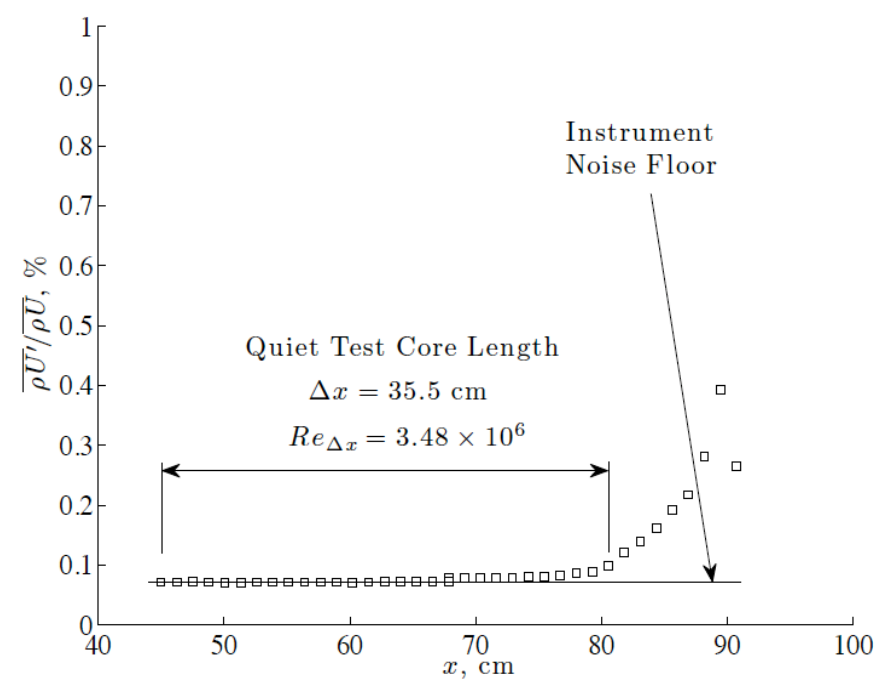

(c) RMS mass-flux along centerline under quiet-flow conditions. Bandwidth was $200 \mathrm{~Hz}$ to $100 \mathrm{kHz}$.

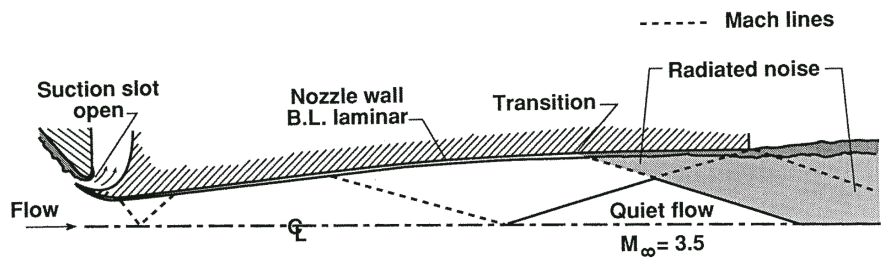

(b) Schematic of quiet test core with bleed valve open for the Mach 3.5 axisymmetric quiet nozzle.

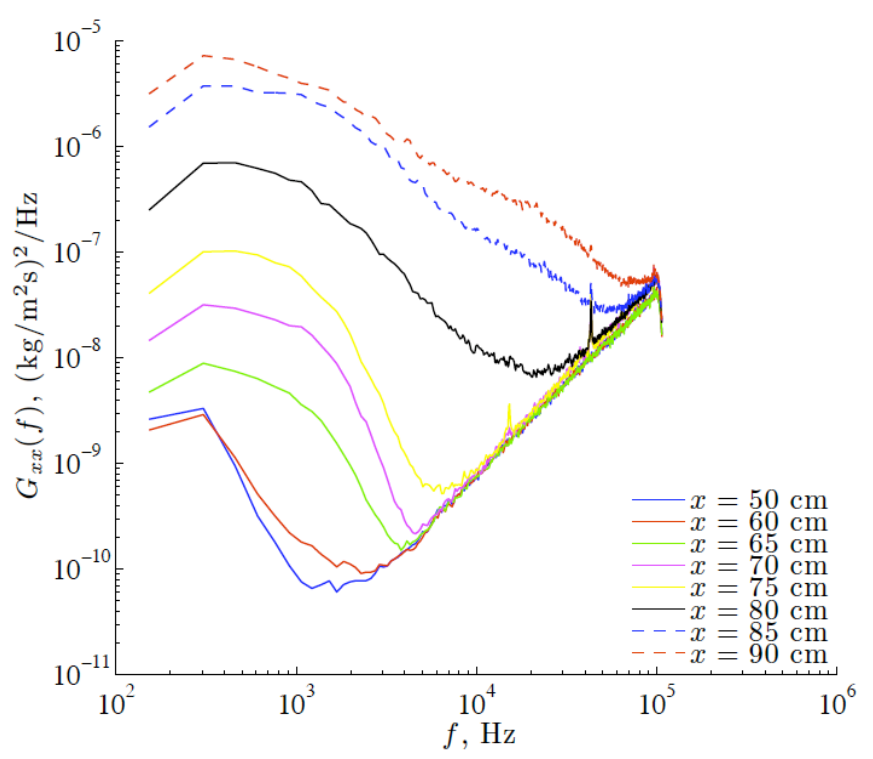

(d) Power spectral density of mass-flux along centerline under quiet-flow conditions.

Figure 1. Illustrations of the SLDT Mach 3.5 axisymmetric nozzle and centerline measurements of mass-flux fluctuations under quiet flow conditions (bleed valves open). $P_{0}=172.4 \mathrm{kPa}, T_{0}=311 \mathrm{~K}$ and $\mathrm{Re} / \mathrm{m}=9.81 \times 10^{6}$.

$\underline{11 \text { of } 22}$

American Institute of Aeronautics and Astronautics 


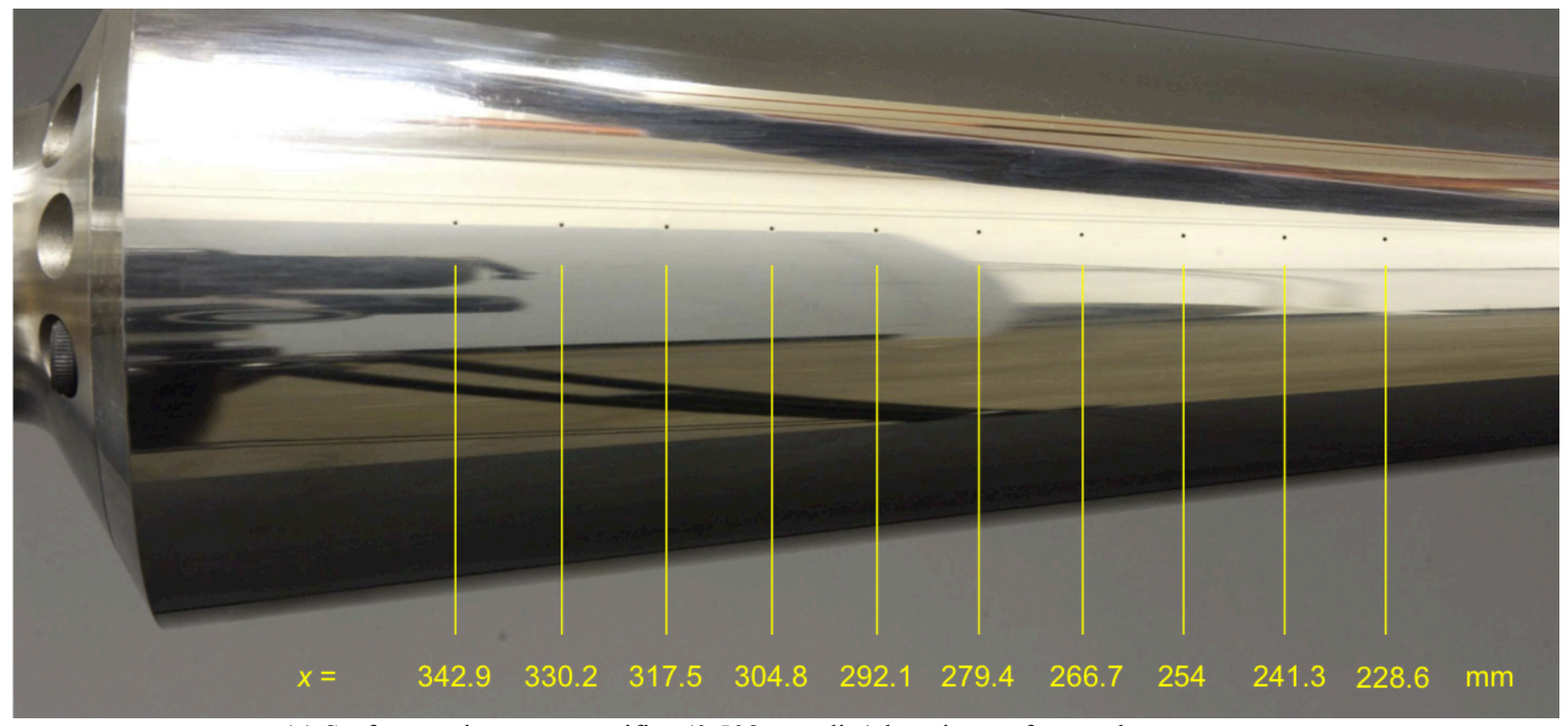

(a) Surface static pressure orifice $(0.508 \mathrm{~mm}$ dia.) locations referenced to cone apex

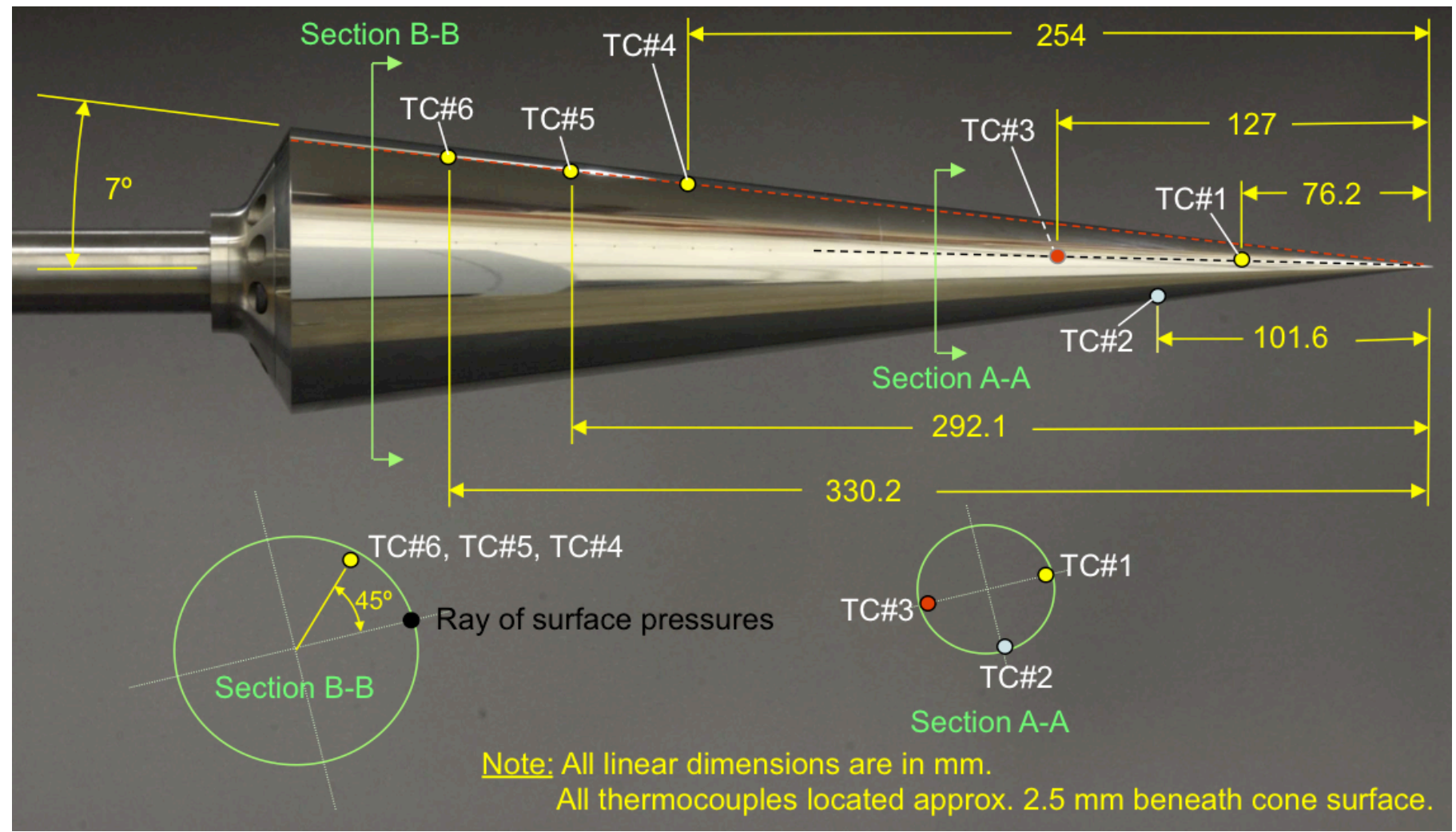

(b) Thermocouple locations referenced to cone apex

Figure 2. Photos show the cone model details and surface instrumentation layout. Note the cone ray with surface static pressures was rotated above side highlight to make sure each orifice would be visible in the image. 


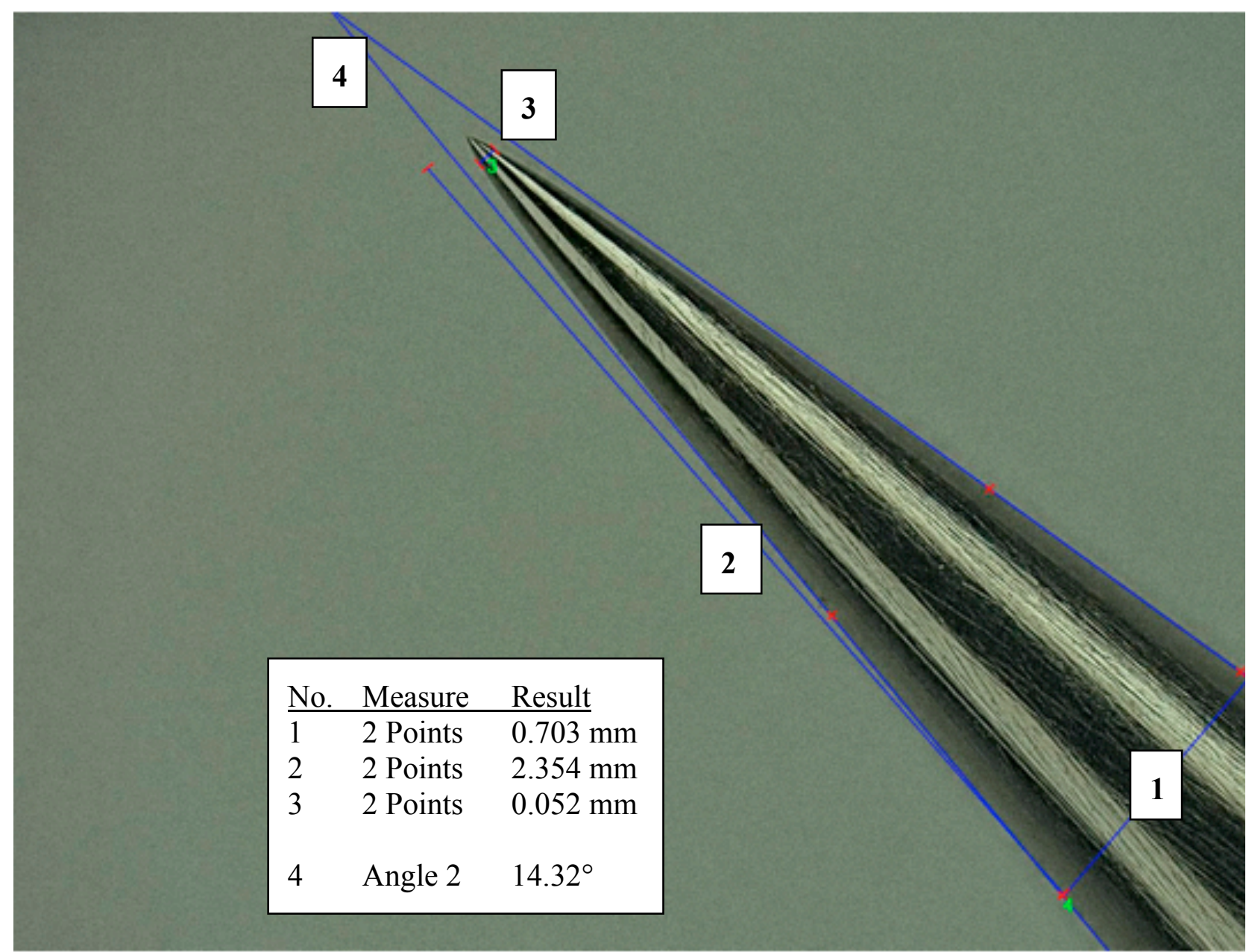

Figure 3. Photo shows a close-up picture (magnification: 100x) of $7^{\circ}$ half-angle cone model nominally sharp tip as tested.

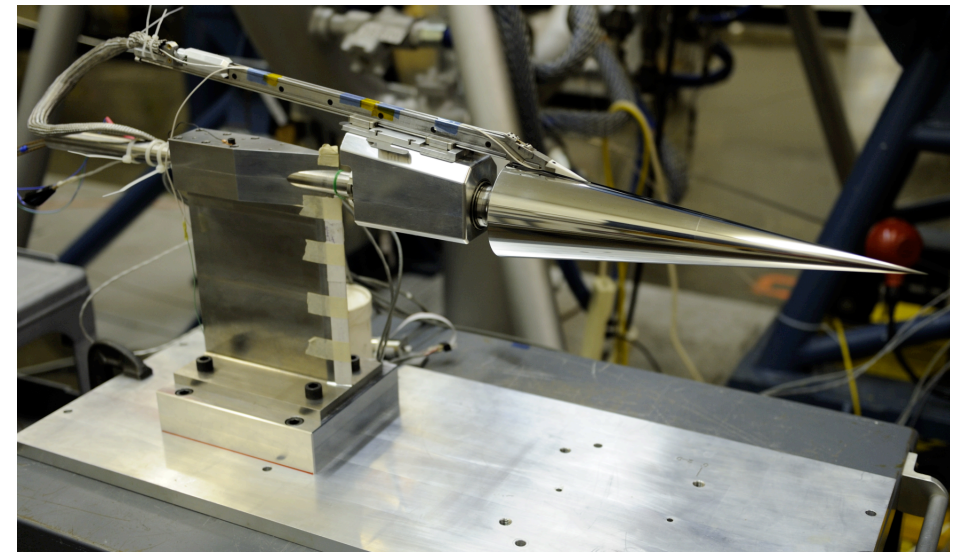

(a) Cone model, traverse and support

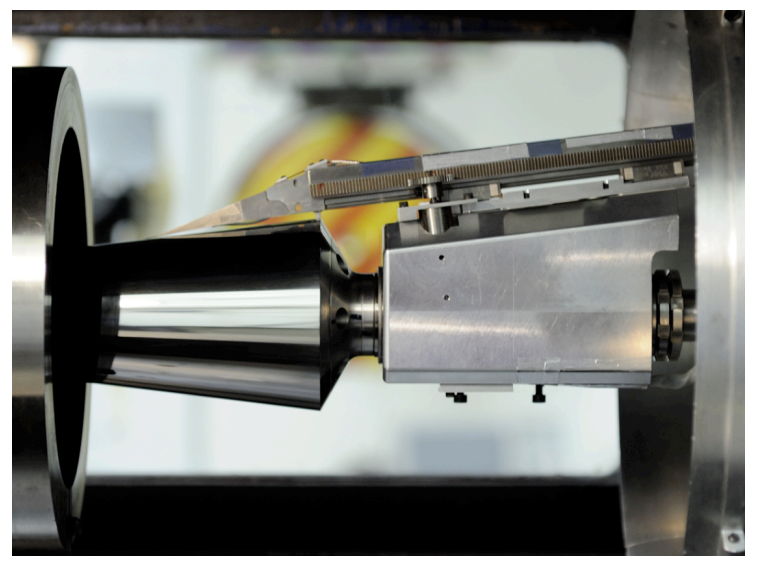

(b) Model system installed in SLDT

Figure 4. Pictures of $7^{\circ}$ half-angle cone model and the off-body probe traverse system as it was tested. 
Probe Body Refinement
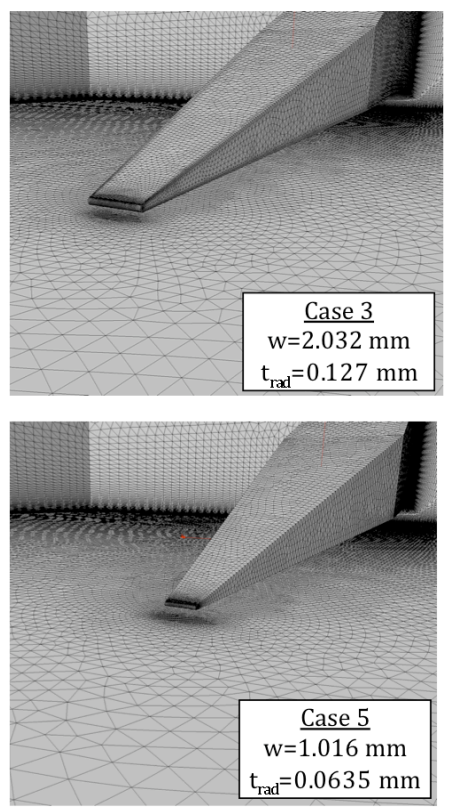

(a) Computational surface grids used in probe design study.

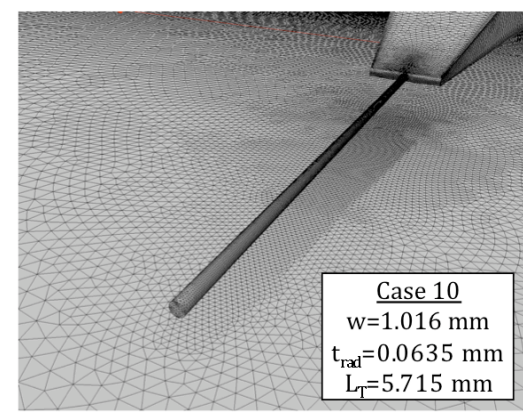

Hot-wire Prong Length
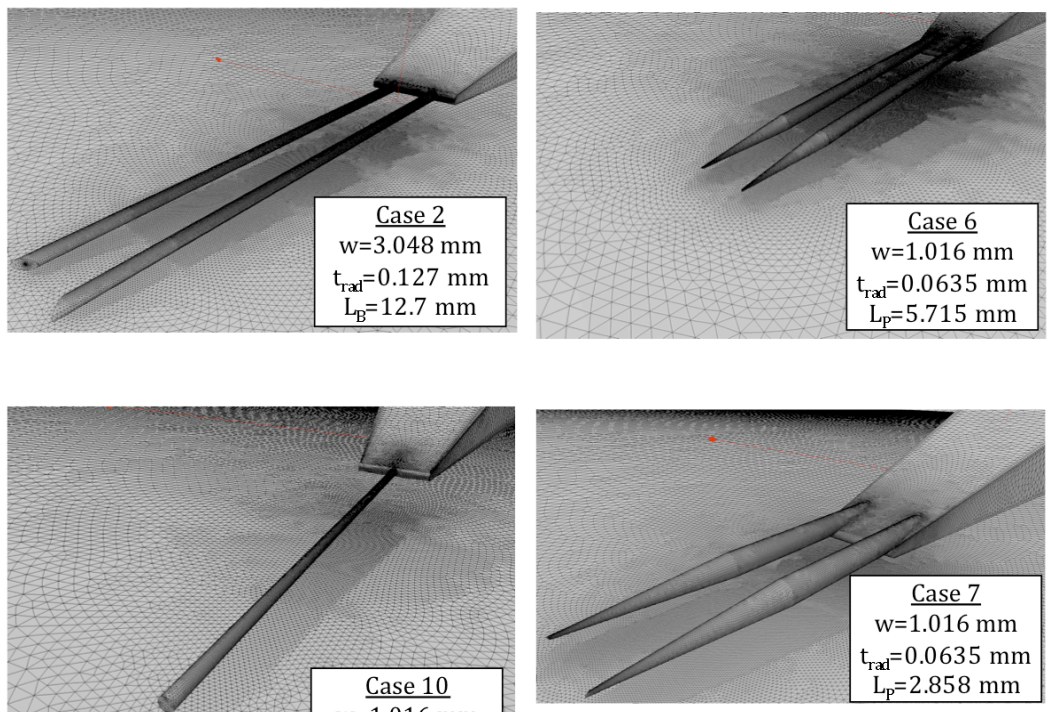

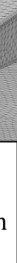

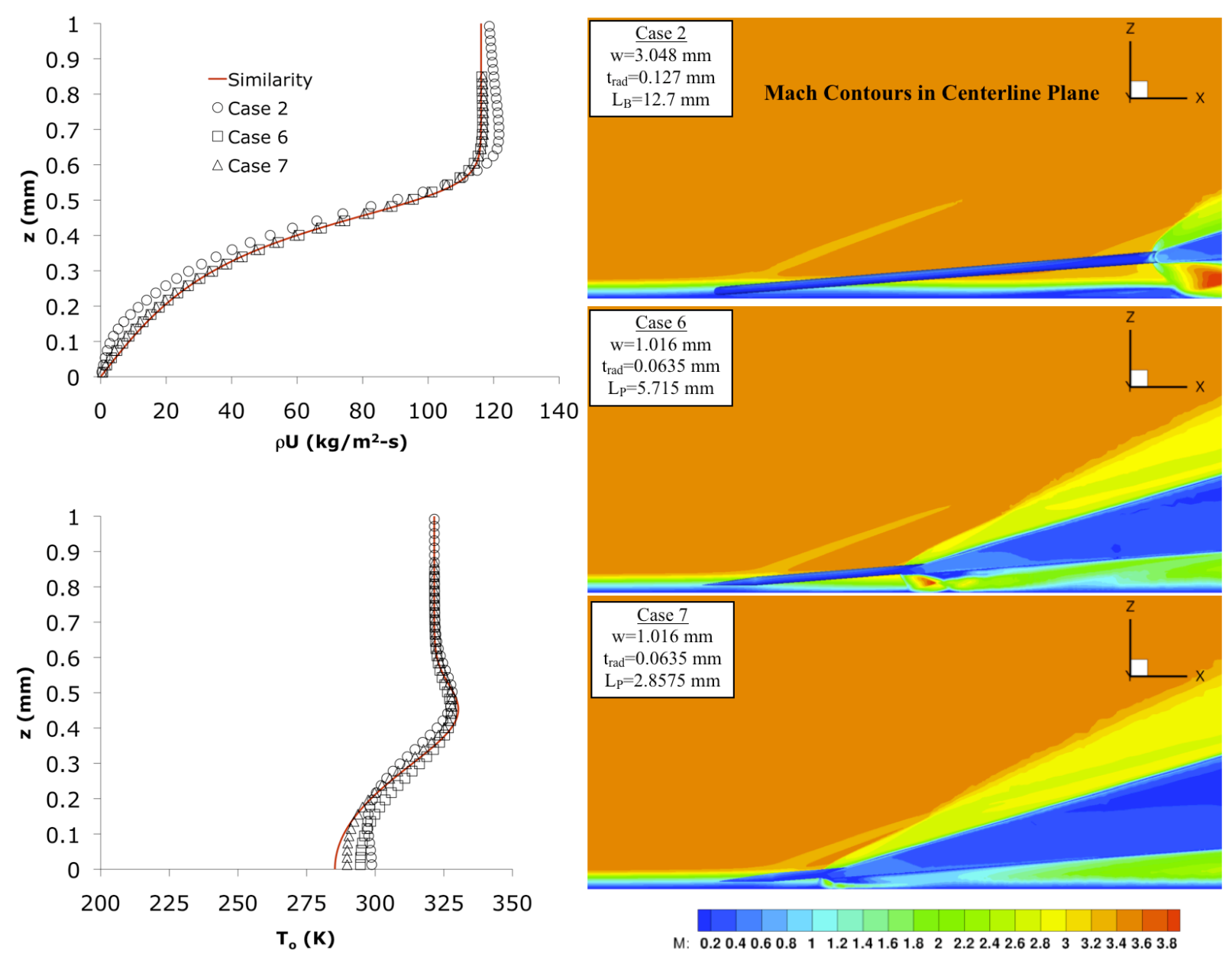

(b) CFD study results showing probe design aerodynamic interference effects.

Figure 5. NASA hot-wire probe CFD (TetRUSS) study on a flat plate.

$$
14 \text { of } 22
$$

American Institute of Aeronautics and Astronautics 


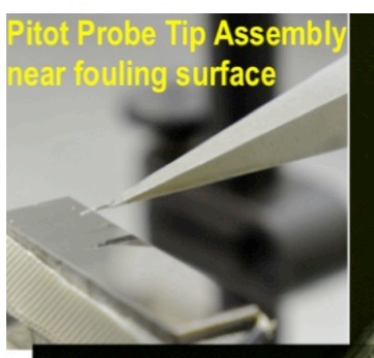

Probe Body Tip (planform)

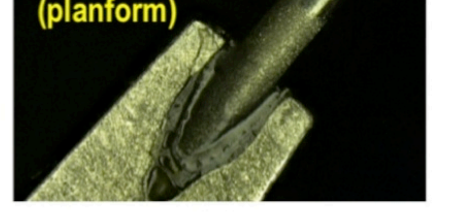

$\mathrm{w}=1.1 \mathrm{~mm}$

$\mathrm{t}_{\mathrm{rad}}=0.064 \mathrm{~mm}$

$\mathrm{L}_{\mathrm{T}}=2.8 \mathrm{~mm}$ (Short Pitot)

Large tube diameter $=0.35 \mathrm{~mm}$

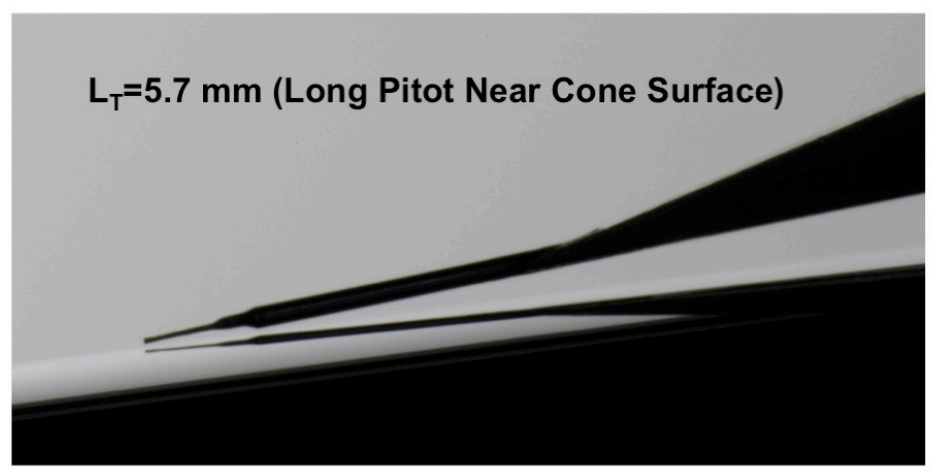

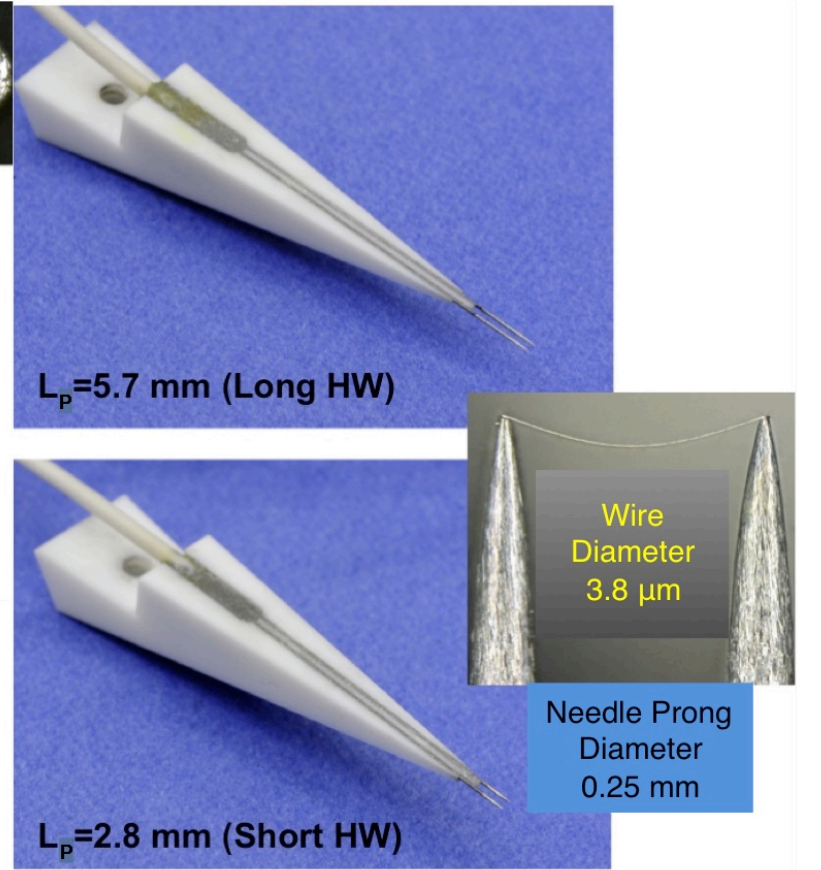

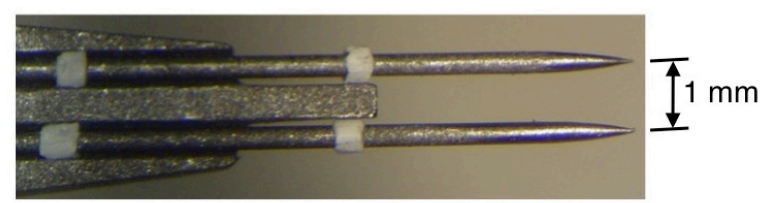

Figure 6. NASA boundary-layer probe designs used in the cone model testing.

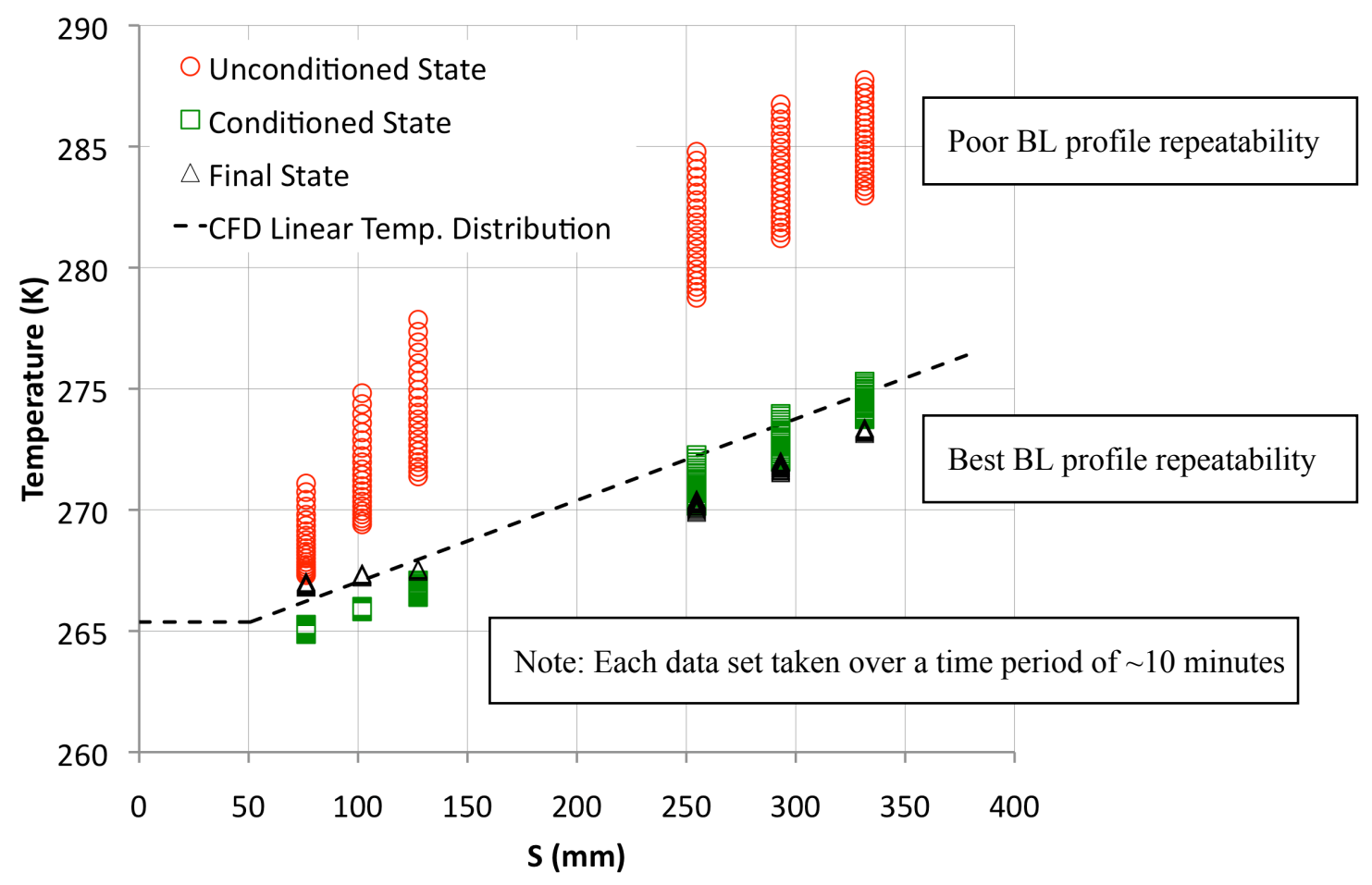

Figure 7. Temperature data shows the effects of thermal conditioning for the thick-walled cone model.

$$
15 \text { of } 22
$$

American Institute of Aeronautics and Astronautics 


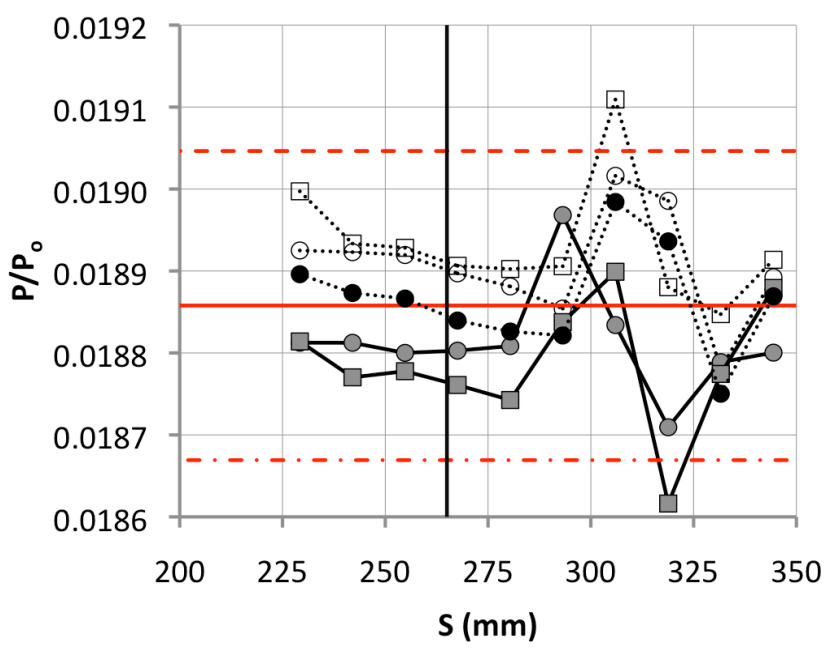

(a) Measured static pressures for different azimuthal angles $\cdot \odot \cdot \operatorname{EXP} 0^{\circ}$

$\multimap \operatorname{EXP} 180^{\circ}$

... $\operatorname{EXP}-90^{\circ}$

$-\square-\operatorname{EXP}+90^{\circ}$

$--\mathrm{CFD}+1 \%$

- CFD (Minf=3.48)

- - CFD-1\%

-. EXP $0^{\circ}$ (after pitch alignment)

- Nozzle Exit at $\mathrm{S}=265 \mathrm{~mm}$

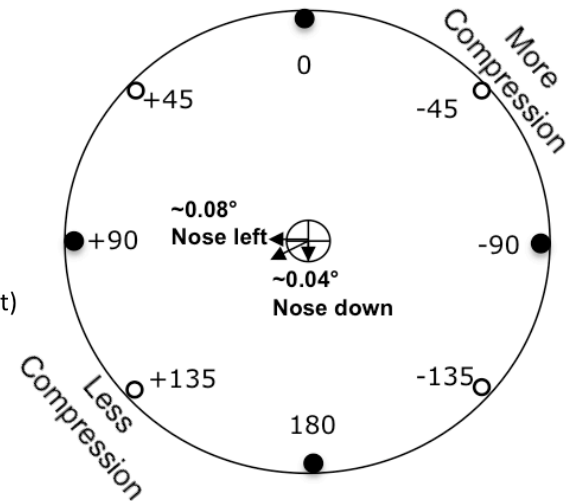

(b) Schematic showing cone ray azimuthal angles at a section looking upstream.

Figure 8. Cone surface static pressure data on different cone rays showing the effects of cone misalignment with nozzle flow. $P_{0}=172.4 \mathrm{kPa}, T_{0}=311 \mathrm{~K}$ and $\mathrm{Re} / \mathrm{m}=9.81 \times 10^{6}$.
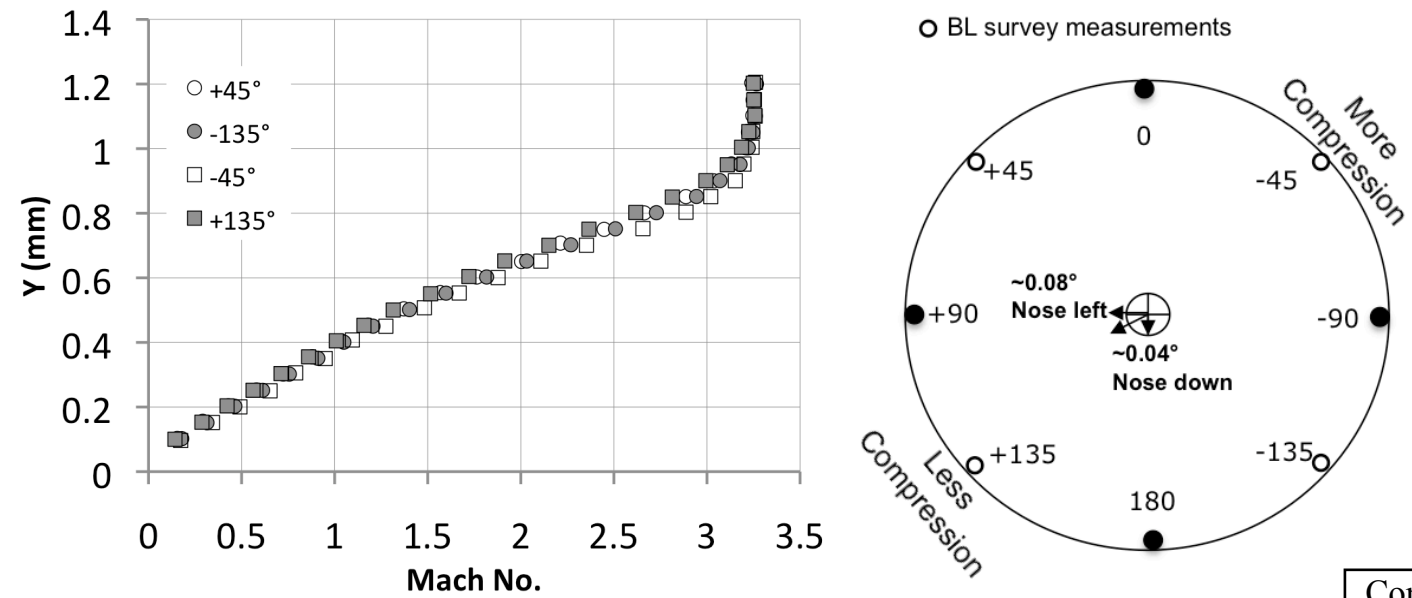

(a) Profiles before adjusting cone pitch alignment to the nozzle flow
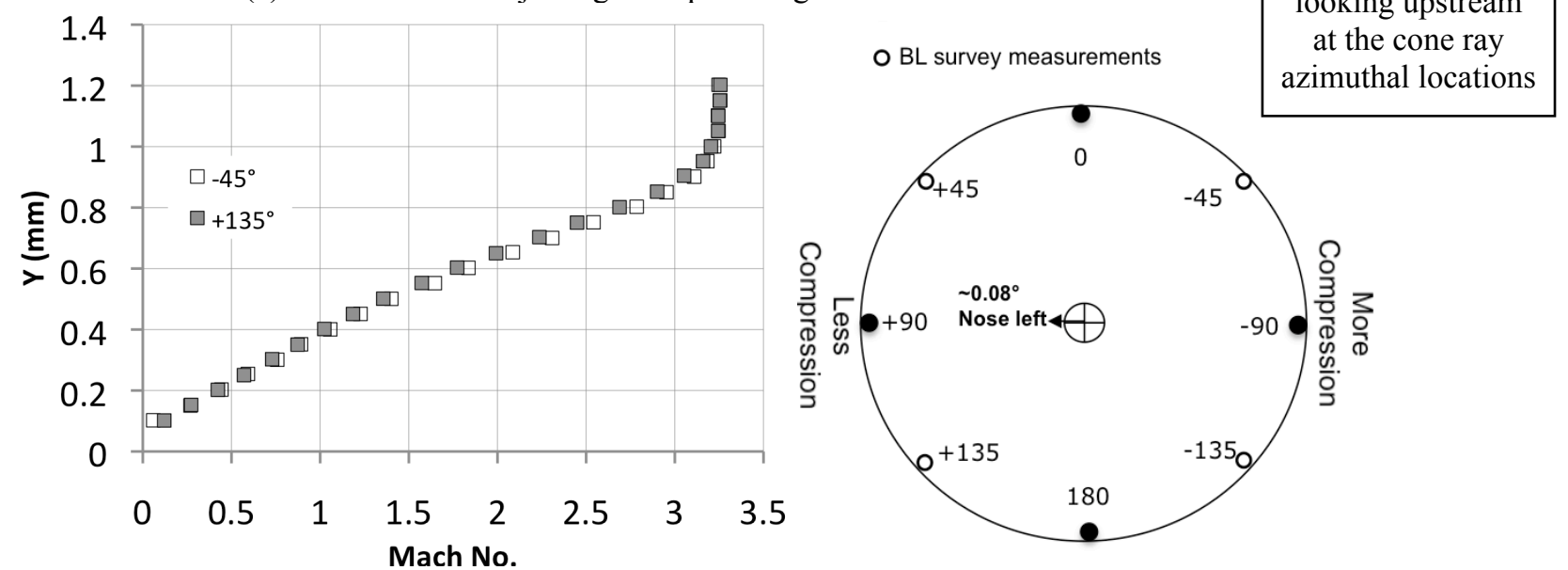

(b) Selected profiles after pitch alignment to the nozzle flow

Figure 9. Cone boundary-layer profile data (long pitot probe) at $S=298 \mathbf{~ m m}$ shows the effects of cone misalignment with nozzle flow. $P_{0}=172.4 \mathrm{kPa}, T_{0}=311 \mathrm{~K}$ and $\mathrm{Re} / \mathrm{m}=9.81 \times 10^{6}$.

16 of 22

American Institute of Aeronautics and Astronautics 


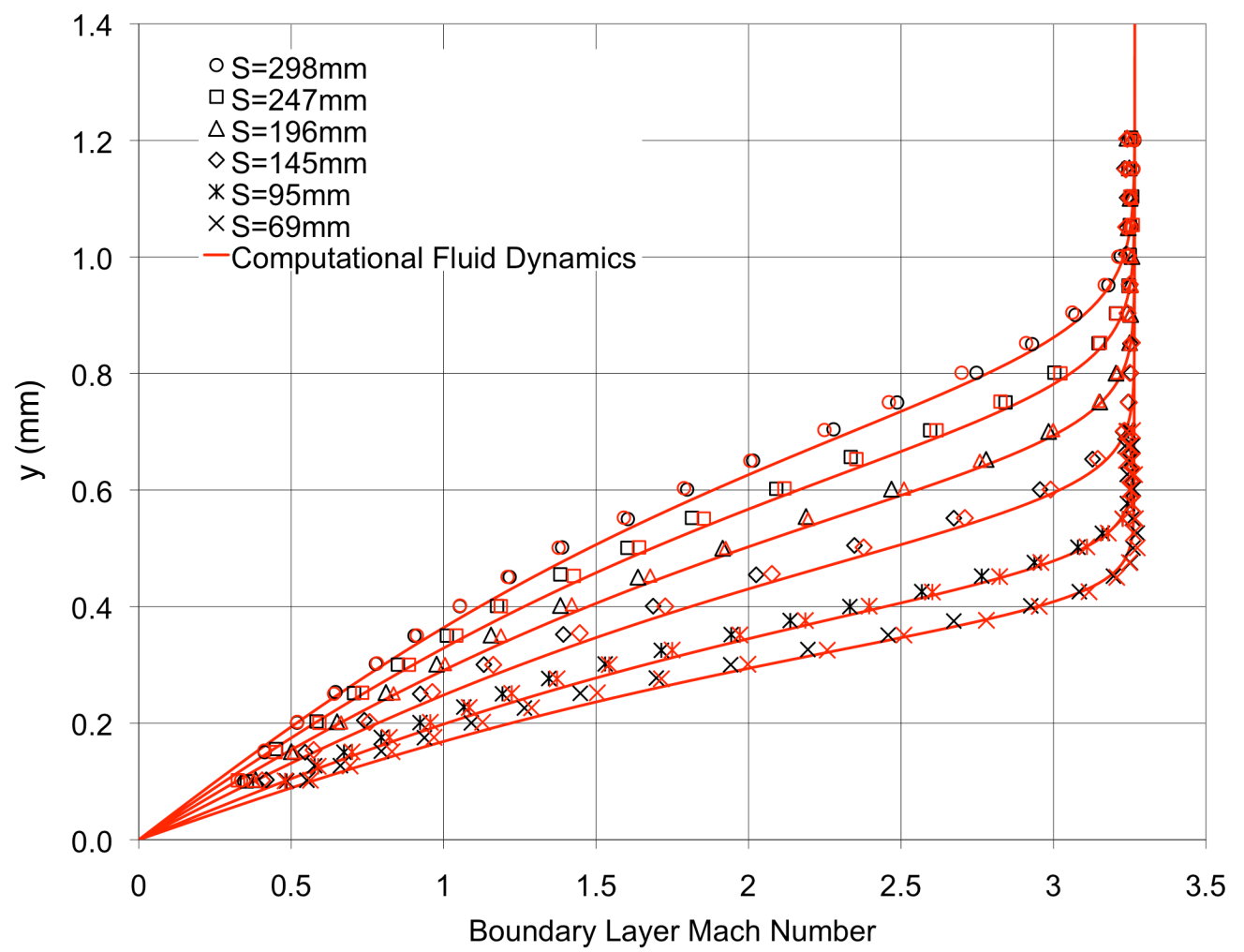

Figure 10. Boundary-layer profile data at different S-locations along a given cone ray $\left(\theta=+135^{\circ}\right)$ shows probe length effect. Red symbols are for long pitot probe data and black symbols are for short pitot probe data. $P_{0}=172.4 \mathrm{kPa}, T_{0}=$ $311 \mathrm{~K}$ and $\mathrm{Re} / \mathrm{m}=9.81 \times 10^{6}$.

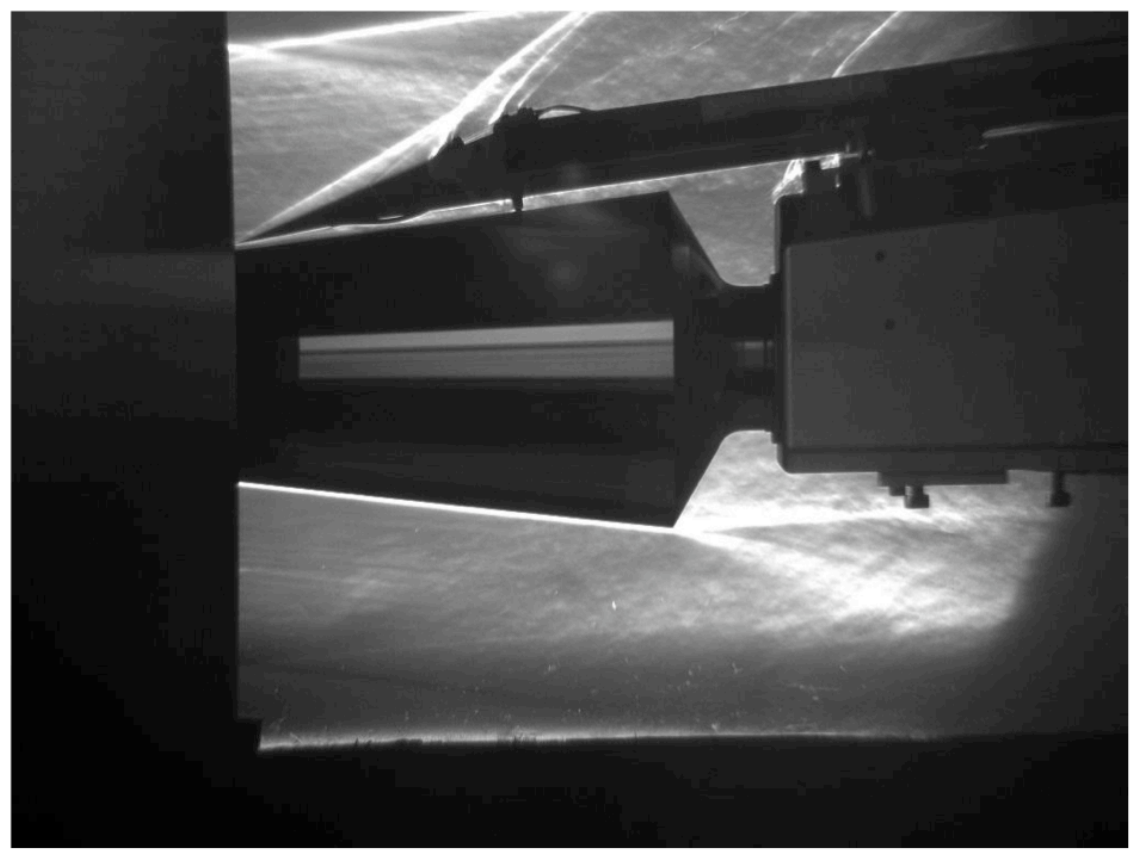

Figure 11. Schlieren image shows the cone model $/$ traverse flow field in the SLDT. $P_{0}=172.4 \mathrm{kPa}, \mathrm{T}_{0}=311 \mathrm{~K}$ and $\mathrm{Re} / \mathrm{m}=9.81 \times 10^{6}$. 


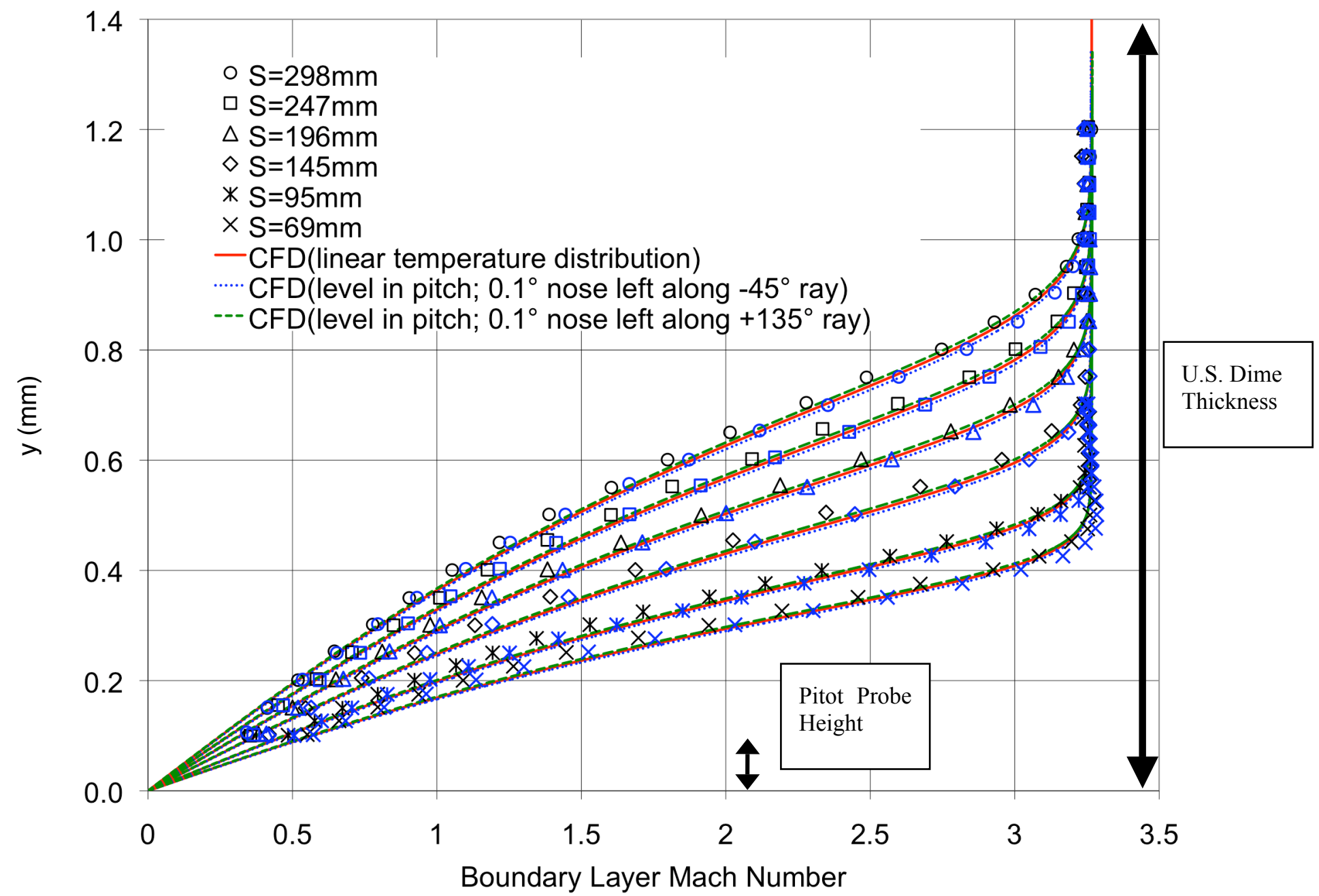

Figure 12. Mean short pitot probe boundary-layer measurement capability compared to CFD with matching boundary conditions. Black symbols for profile measurements along cone ray of $\theta=+135^{\circ}$ and blue symbols are for $\theta=-45^{\circ}$ (see Fig. 9 for $\theta$ orientation). $P_{0}=172.4 \mathrm{kPa}, T_{0}=311 \mathrm{~K}$ and $R e / m=9.81 \times 10^{6}$. 

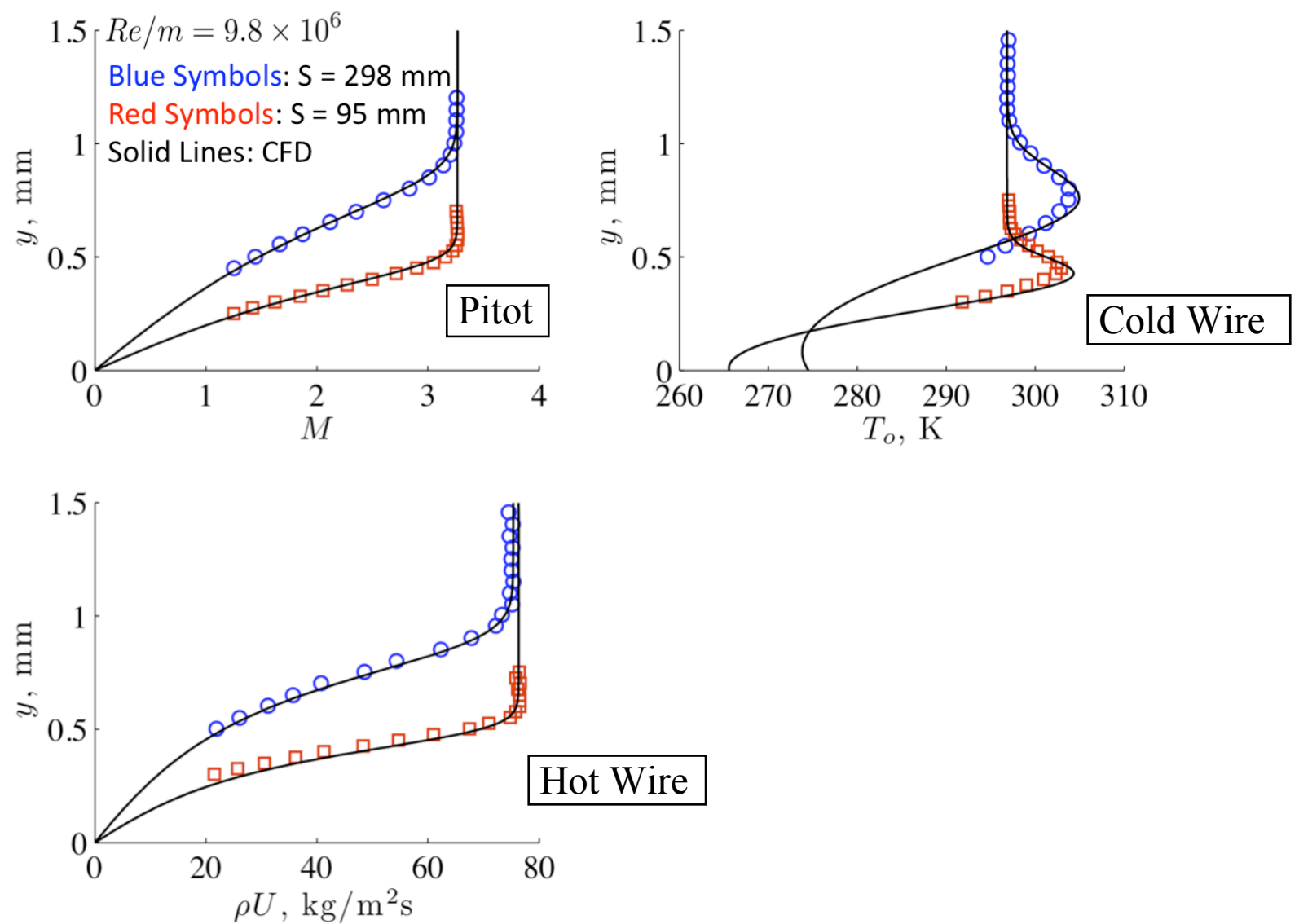

Figure 13. Mean short hot-wire probe boundary-layer measurement capability compared to CFD with matching boundary conditions $\left(\theta=-45^{\circ}\right)$.

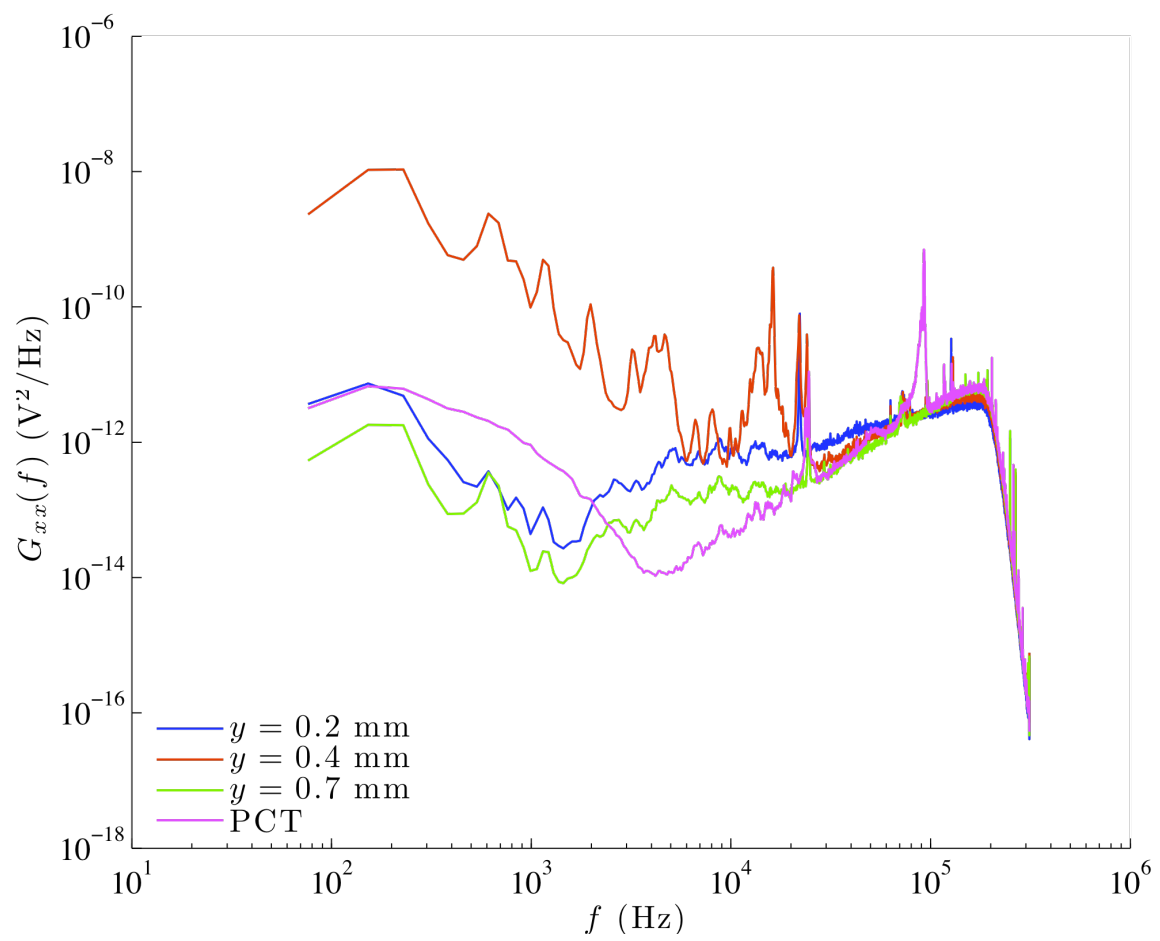

Figure 14. Voltage Spectra in Cone boundary layer $69 \mathrm{~mm}$ downstream of cone tip $\left(\theta=-45^{\circ}\right)$ at various heights in the boundary layer compared to calibration spectra from the Probe Calibration Tunnel.

19 of 22

American Institute of Aeronautics and Astronautics 


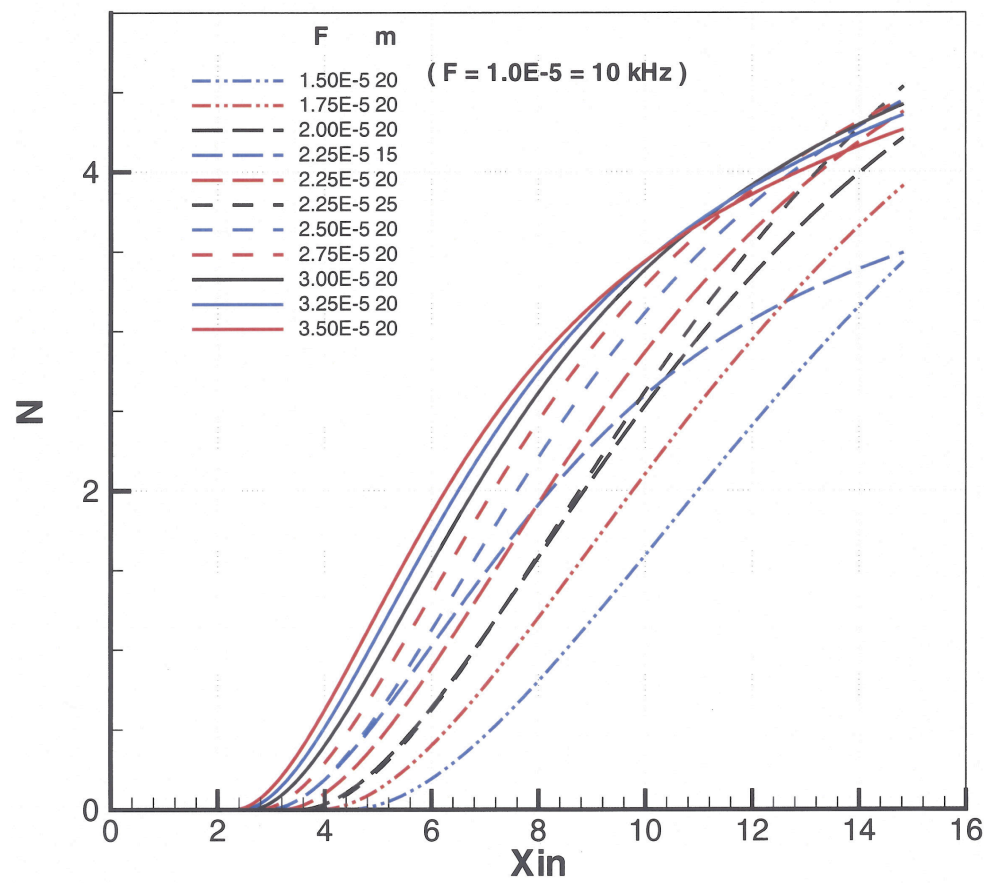

Figure 15. Stability analysis for $7^{\circ}$ half-angle cone model showing disturbance growth (N-factor) for the low Reynolds number test condition. $M=3.5, P_{0}=172.4 \mathrm{kPa}, \mathrm{T}_{0}=311 \mathrm{~K}$ and $\mathrm{Re} / \mathrm{m}=9.81 \times 10^{6}$.

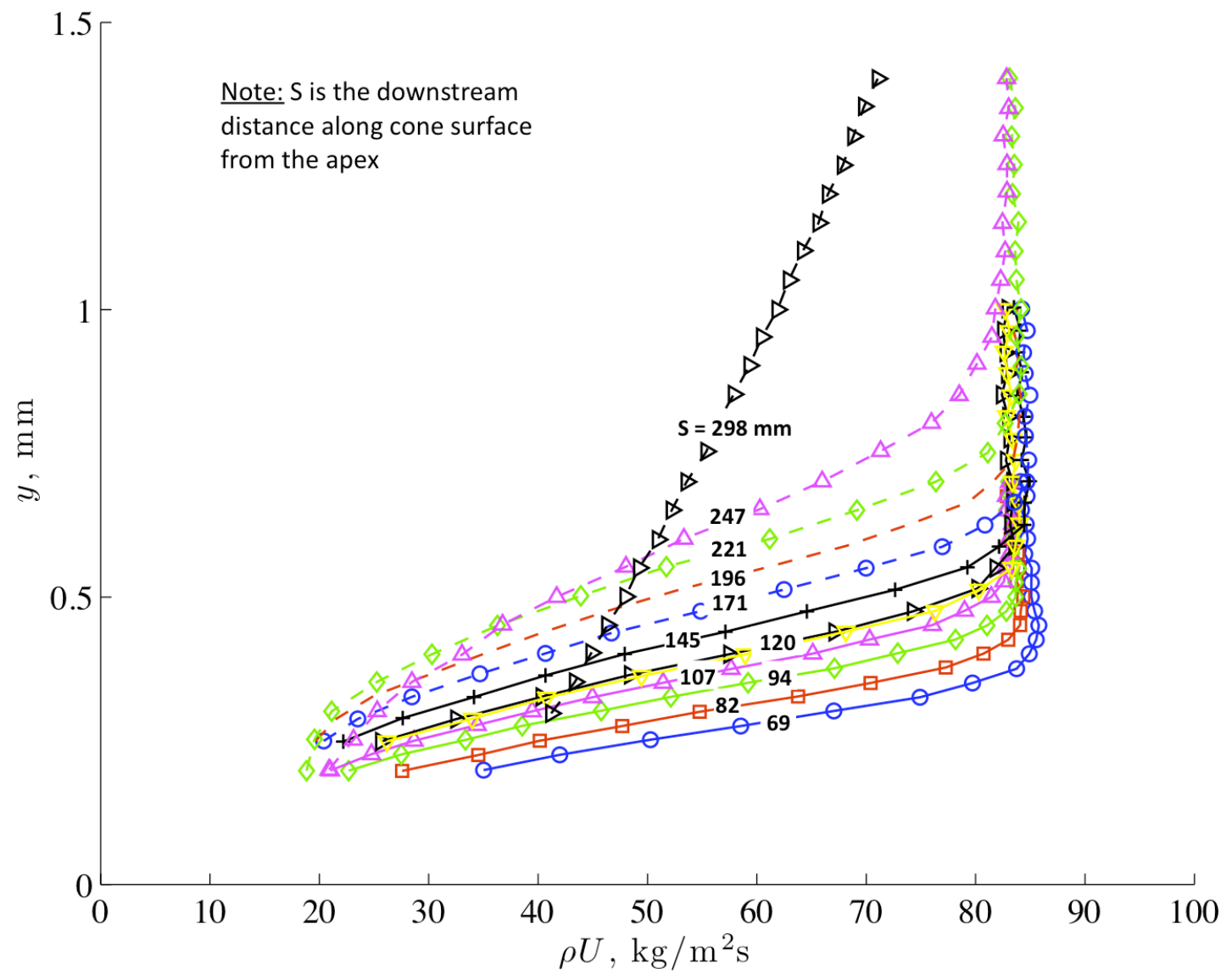

Figure 16. Calibrated hot-wire mean mass-flux profile data $\left(\theta=-45^{\circ}\right)$ for high disturbance flow conditions $($ bleed valves closed). $P_{0}=172.4 \mathrm{kPa}, T_{0}=311 \mathrm{~K}$ and $\mathrm{Re} / \mathrm{m}=9.81 \times 10^{6}$.

20 of 22

American Institute of Aeronautics and Astronautics 


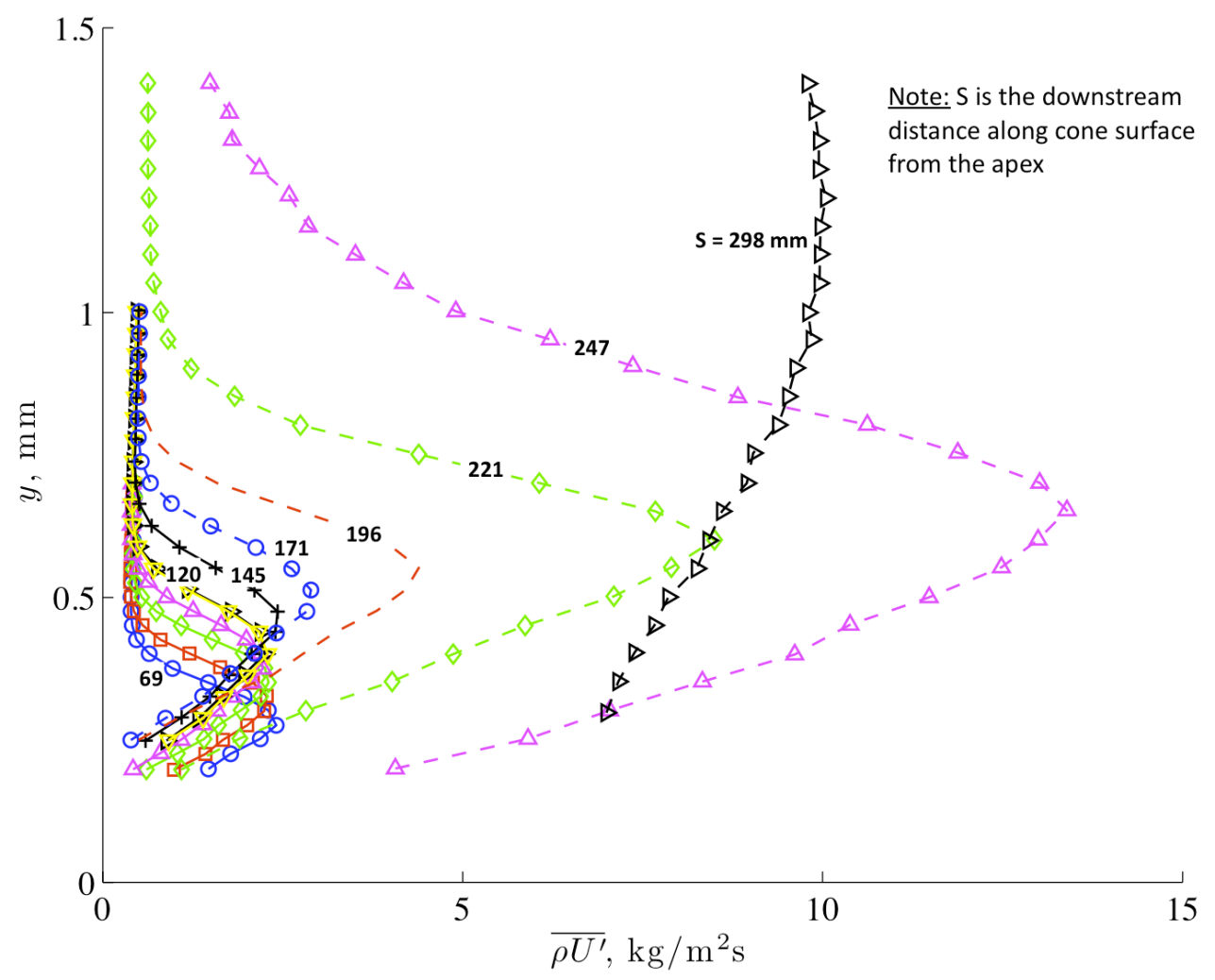

(a) RMS mass-flux profiles at different cone stations.

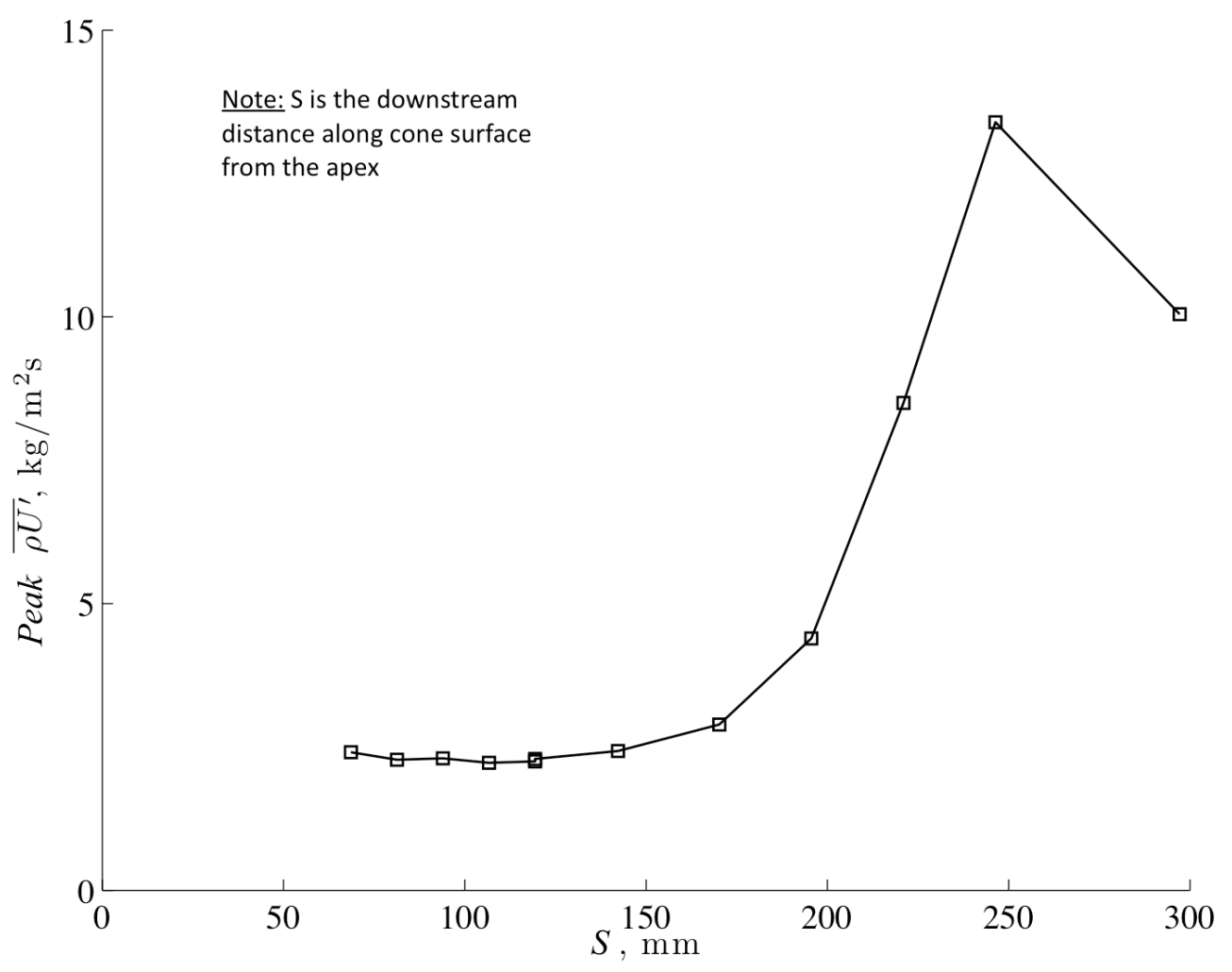

(b) Peak RMS mass-flux variation along a cone ray.

Figure 17. Fluctuating mass-flux profile data $\left(\theta=-45^{\circ}\right)$ for high disturbance flow conditions (bleed valves closed). $P_{0}=$ $172.4 \mathrm{kPa}, \mathrm{T}_{0}=311 \mathrm{~K}$ and $\mathrm{Re} / \mathrm{m}=9.81 \times 10^{6}$. 

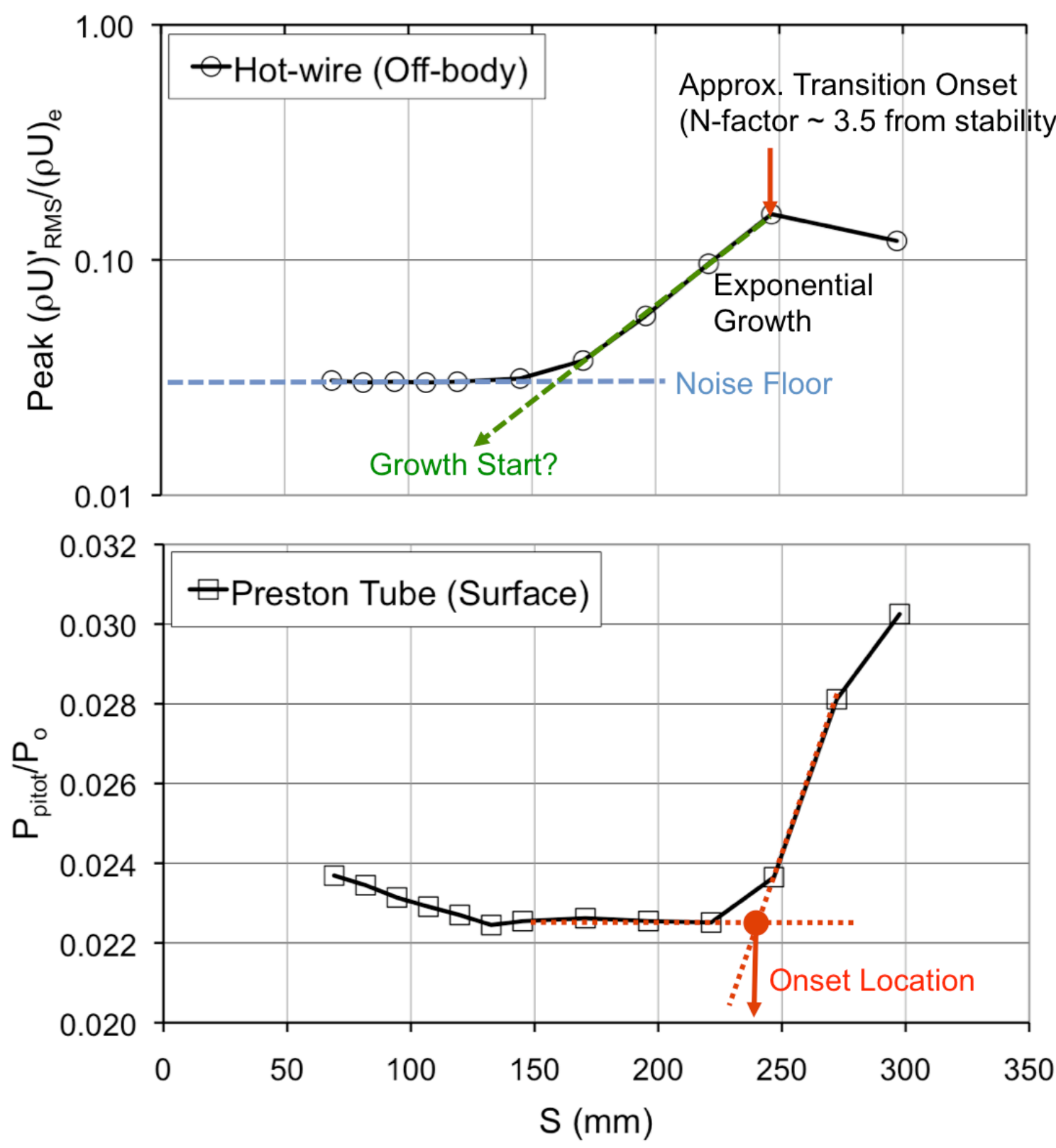

Figure 18. A comparison of off-body and surface transition onset locations $\left(\theta=-45^{\circ}\right)$ on the $7^{\circ}$ half-angle cone model for high disturbance flow conditions (bleed valves closed). $M=3.5, P_{0}=172.4 \mathrm{kPa}, \mathrm{T}_{0}=311 \mathrm{~K}$ and $\operatorname{Re} / \mathrm{m}=9.81 \times 10^{6}$. 